\title{
Inflation, Money Demand and Portfolio Choice*
}

\author{
Kosuke Aoki ${ }^{\dagger}$ \\ London School of Economics
}

\author{
Alexander Michaelides ${ }^{\ddagger}$ \\ Central Bank of Cyprus and \\ London School of Economics, CEPR, FMG and Netspar
}

Preliminary draft, February 2010

*We thank the Central Bank of Cyprus and the Bank of England for hospitality when this paper was written. We are responsible for any remaining errors.

${ }^{\dagger}$ London School of Economics, Houghton Street, WC2A 2AE, UK. E-mail: k.aoki@lse.ac.uk

${ }^{\ddagger}$ LSE, Houghton Street, London, WC2A 2AE, UK, CEPR and FMG. Email: A.Michaelides@lse.ac.uk. 


\begin{abstract}
We investigate the effects of inflation on life-cycle saving and asset allocation. To achieve this goal, we estimate the preference parameters that can simultaneously match the holdings of money, bonds and stocks over the life cycle. Poor households tend to hold money for liquidity reasons. Richer households incur a fixed (financial sophistication) cost and hold simultaneously money, bonds and stocks. The model allows us to quantify the effects of inflation on money demand, saving and asset allocation. We use the model to quantify how inflation (and monetary policy) affects aggregate consumption demand by changing the real value of nominal assets, causing redistribution of wealth among different agents. In a similar token, we investigate the predicted responses of portfolio choices in response to inflation changes for the wealthier part of the population that hold most of the nominal stocks.

JEL Classification: G11.

Key Words: Life Cycle Models, Portfolio Choice, Inflation, Money Demand, Preference Heterogeneity, Liquidity Constraints, Uninsurable Labor Income Risk.
\end{abstract}




\section{Introduction}

In the recent large literature on portfolio choice ${ }^{1}$ households are assumed to invest between different real assets (typically bonds, stocks and/or housing), ignoring the fact that all transactions in the data are actually done in nominal terms. These models therefore cannot study the effects of inflation on the real economy, money demand or household portfolio choice decisions. On the other hand, the monetary economics literature starts out with a nominal model and inflation becomes a key driver of results and implications for policy. Nevertheless, canonical models in the money demand literature follow the Baumol-Tobin analysis and typically focus on the distinction between money and all other assets lumped together in the household portfolio.

However, a potentially more important decision (especially for the richest part of the population) involves the asset allocation between transaction-type balances (like money) and stocks (that have a substantially different risk-return tradeoff from bonds). As is documented by Doepke and Schneider (2006), inflation changes the real value of nominal assets. Thus both the level and volatility inflation have the potential of affecting household portfolio choice by changing the real returns of assets. Furthermore, a large majority of households (especially poorer households) do not hold either bonds or stocks, holding only money or checking accounts. For these households an important decision is not on investing either in bonds or stocks (or both), but whether or not they decide to hold any interest-bearing assets at all. We build and estimate the preference parameters of a model that explicitly includes money, bonds and stocks in the portfolio, and we can therefore study the effects of inflation on saving and portfolio choice over the life cycle.

Our research strategy first involves determining the participation and port-

\footnotetext{
${ }^{1}$ See Campbell (2006) for a recent excellent survey.
} 
folio choices of households over the life cycle in these three broad asset classes in the data. We use the US $2001 \mathrm{SCF}$ for this purpose and find that $90 \%$ of households have liquid accounts and $52 \%$ stocks and $63 \%$ bonds. On the other hand, very few households have no liquid accounts but simultaneously invest in either bonds or stocks. Also, richer households tend to hold less money and more stocks as a percentage of their total financial assets. These facts suggest that limited participation to any interest-bearing assets (as opposed to limited participation in stock market emphasized in the portfolio choice literature) is a key feature of the data.

To analyze the effect of inflation on the real economy in this setup we first need to introduce a role for money balances in the model. Introducing money can vary in complexity from the micro-founded Kiyotaki and Wright (1989) setup to the more reduced form models such as the cash-in-advance (Lucas and Stokey (1987)), money-in-utility function (Sidrauski (1967)) and the shoppingtime approach (McCallum and Goodfriend (1987)). Given that our purpose is to develop a tractable model that can be confronted with the data, we use a reduced form approach similar to shopping time models. ${ }^{2}$ Specifically, we assume that money provides liquidity services and therefore a higher amount of money lowers the cost from having to undertake a given transaction for consumption purposes, other things being equal. Everything else we assume is similar to recent life-cycle models that feature intermediate consumption and stochastic uninsurable labor income in the tradition of Deaton (1991) and Carroll $(1997)^{3}$, and as extended in the life cycle portfolio choice literature by Cocco et al. (2005), for instance. One nice feature of our setting is that it

\footnotetext{
${ }^{2}$ For recent applications of shopping time models, see, for example, Mulligan and Sala-iMartin (2000).

${ }^{3}$ Attanasio et al. (1999), Gourinchas and Parker (2002) and Cagetti (2003) extend this tradition and estimate the structural parameters of life cycle models with a single real asset (a riskless bond).
} 
nests the life cycle portfolio models where bonds and stocks are real assets and money does not circulate in the economy.

Given the lack of guidance for picking the shopping technology parameters, we estimate these using a method of simulated moments (MSM) estimation technique. We estimate the structural parameters by matching moments from the 2001 Survey of Consumer Finances data and simulated data from the model. Specifically, we match mean financial wealth over mean labor income over the life cycle, and the portfolio shares across money, bonds and stocks for the investors in the model. We use ex ante preference heterogeneity to mimick the behavior of the poorest segment of the population that holds only money in their financial portfolio.

Given that we have a model that resembles the data, we can use the model to provide answers to interesting questions. Examples of such questions follow. What are the effects of both the level and volatility of inflation on money demand and asset allocation? Can inflation have real, aggregate demand effects in the model? What are the hedging demands generated by inflation? Given the heterogeneity of consumption and wealth outcomes in the model, what are the redistributive effects of inflation as in Doepke and Schneider (2006).

Can we say something about the elasticity of intertemporal substitution? An important concept in the literature on monetary policy transmission is the elasticity of intertemporal substitution (EIS) because it determines how aggregate demand responds to a change in policy interest rate. Typically, models used for the analysis of monetary policy employ the representative household framework (see, for example, Christiano et al. (2005)). The consumption Euler equation for safe nominal bounds is interpreted as representing the aggregate demand side of the economy, and the EIS is calibrated to match aggregate 
data. However, Vissing-Jorgensen (2002) shows that limited participation in asset markets can be an important concern when estimating the EIS. This indicates that understanding better the monetary policy transmission mechanism might require incorporating agent heterogeneity and limited participation in macro models, what we view as a promising avenue for further research.

In terms of the literature, we view the paper as contributing towards understanding money demand and portfolio choice in the presence of nominal assets. Typically, research on money demand focusses on the distinction between money and all other assets (see, for example, Mulligan and Sala-i-Martin (2000), Alvarez and Lippi (2009)). In our model we make explicit the choice between money (that earns a zero nominal return) and other assets like bonds and stocks that earn the historically observed rates of return. While the literature mainly focuses on demand for money for transaction services, our finding in Section 2 implies that the poorer households hold only money in their financial portfolio. Our model generates cash holdings for both transaction and saving purposes. Early contributions in this regard are Chatterjee and Corbae (1992) and Erosa and Ventura (2002). Compared with their contributions, our model features richer heterogeneity in terms of life-cycle decisions and portfolio choices among riskier assets so that the model can be matched more readily to the data. Moreover, we estimate the structural parameters of a life cycle model that can replicate the observed demands and therefore we offer some guidance into how the structural model can be extended in the future to address interesting macroeconomic questions. The other strand of the literature that the model relates to is the recent life cycle saving and portfolio choice literature (Cocco et al. (2005), Gomes and Michaelides (2003, 2005), Polkovnichenko (2007) and Wachter and Yogo (2009) to name some examples). In all these papers, however, the choice is between real assets (real bonds and real stocks) 
and therefore the effects of inflation cannot be analyzed. Also, we document that a non-negligible fraction of households do not hold any interest-baring assets (except money), which the existing portfolio literature typically abstracts from. Our work is closest to the paper by Gomes and Michaelides (2005) who analyze a similar model to ours with preference heterogeneity to generate poor and rich households but without a role for money and therefore without the ability to analyze the effects of inflation on life cycle money demand and asset allocation decisions.

The rest of the paper is organized as follows. Section 2 generates some stylized facts with regards to money holdings over the life cycle section $X$ concludes.

\section{Empirical Evidence on Life Cycle Asset Al- location and Participation in Different Asset Markets}

We focus on using a single cross section, the 2001 Survey of Consumer Finances, for establishing certain stylized facts about the holdings of money in household portfolios over the life cycle. We have repeated the analysis below for all triennial surveys between 1989 and 2007 and we can report that the results from the 1998, 2001, 2004 and 2007 surveys are very similar along the dimensions we report below. Earlier surveys (the 1989 for example) feature lower stock market participation and higher shares of money in the portfolios. The rise of the equity culture in the 1990s is probably responsible for this change. This points towards having to come up with identifying assumptions to decompose the cross sectional results into age, time and cohort effects in 
this earlier period. Instead of following this approach, we compare the results across the 1998 and 2007 surveys and find that our stylized facts are robust both qualitatively and quantitatively across these four surveys. Cohort effects seem to be less important in this period and we therefore interpret the cross sectional evidence as life cycle implications a good monetary model will need to explain. We therefore leave to future work this decomposition that could be quite important in understanding the evolution of money demand in the last three decades.

In the data, most households have a liquid account to undertake their transactions. In the 2001 SCF $91 \%$ of all households had a transactions/liquidity account, $63 \%$ had a positive amount of bonds and $52 \%$ participated in the equity market (including participation through retirement plans) ${ }^{4}$. Our eventual model will attempt to explain these facts using the idea that a fixed cost prevents households from participating in the bond and stock market after opening a transactions account (see Mulligan and Sala-i-Martin (2000) and Gomes and Michaelides (2005), among others, for further exposition). For this story to hold it must be the case that very few households have no liquid accounts but are simultaneously invested in either bonds or stocks. We find that $0.48 \%$ of all households in 2001 fall into this category and this turns out to be close to the highest number across all surveys between 1989 and 2007. Given the broad definition of asset classes we have used to define liquid balances, we think that we can proceed in developing the model with the fixed cost interpretation. We can also compute the mean asset allocations across money, bonds and stocks for the households that hold all three assets. We

\footnotetext{
${ }^{4} \mathrm{By}$ comparison, in the 1989 survey $85.4 \%$ of households have the same transaction accounts, $67.9 \%$ participate in the bond market and $31.8 \%$ participate in the stock market. We make this comparison because thereafter there has been a steady rise in stock market participation mostly through retirement accounts (see Gomes et al. (2009) for example). Thus, the 1989 data are the ones furthest from the 2001 we focus on.
} 
Life Cycle Financial Wealth Accumulation

\begin{tabular}{lll}
\hline \hline Age Group & $\begin{array}{l}\text { Mean (Median) Wealth } \\
\text { No Bonds/Stocks }\end{array}$ & $\begin{array}{l}\text { Mean (Median) Wealth } \\
\text { With either Bonds or Stocks }\end{array}$ \\
\hline $20-34$ & $1454(290)$ & $69386(13450)$ \\
$35-45$ & $3086(400)$ & $137095(42100)$ \\
$46-55$ & $3333(400)$ & $296958(72700)$ \\
$56-65$ & $4458(400)$ & $471997(103400)$ \\
$66-75$ & $9249(1000)$ & $399217(97350)$ \\
\hline
\end{tabular}

Table 1: Mean (median) financial wealth for the two main groups (bond/stockholders and households with only a transaction account) from the 2001 SCF data. The precise definitions for the different variables are in Appendix A

find that the share of wealth in stocks is $37.6 \%$ (with a standard deviation of $34.4 \%$ ), the share of wealth in money is $22.4 \%$ (with a standard deviation of $22.5 \%$ ) and finally the share of wealth in bonds is $40 \%$ (with a standard deviation of $33.4 \%)$.

One of the well-known stylized facts in the life cycle portfolio choice literature is that financial wealth is correlated with stock market participation (see Campbell (2006) for a recent survey). In this spirit (but with different focus) we estimate the mean amount of financial wealth for households with no bonds or stocks but just liquid accounts. The mean amount of financial wealth for this group equals 4162 US\$, whereas for the group that holds either bonds or stocks (and typically also holds a liquid account) mean financial wealth equals 260206 US\$ illustrating the stark dichotomy between households that hold bonds and stocks and households that just hold transaction accounts. Table 1 reports the levels of financial assets across the two groups over five broad age categories (four during working life and one during retirement).

This table shows that poor households tend to hold just liquid balances in the form of money and deposits, while richer households tend to invest in higher return assets. We can also compute the mean asset allocations across 
money, bonds and stocks for the households that hold all three assets. We find that the share of wealth in stocks is $37.6 \%$ (with a standard deviation of $34.4 \%$ ), the share of wealth in money is $22.4 \%$ (with a standard deviation of $22.5 \%$ ) and finally the share of wealth in bonds is $40 \%$ (with a standard deviation of $33.4 \%)$.

A second issue that is well known in the literature that comes out from Table 1 is the skewed distribution of financial wealth which affects the choices researchers need to make when bringing models to the data. In general, there are three main mechanisms being used to match the observed wealth distribution: heterogeneous discount rates (Krusell and Smith (1998)), bequests (De Nardi (2004)), and a combination of bequests and entrepreneurship (Castaneda et al. (2003)). These are general equilibrium models with a single asset, whereas we want to eventually solve a model with three different assets and different rates of return. Rather than complicating the model further we abstract from most of these issues and do not match the wealth distribution exactly. Instead we focus on matching the ratio of mean financial wealth to mean labor income, the idea being that a general equilibrium model can be calibrated to match these magnitudes eventually. We leave again the more ambitious task of matching the wealth distribution in the context of this monetary model to future work. The targets of the model estimation in Section X are given in table 2.

We next go deeper into the role of money in the household portfolio and how money allocations change over the life cycle. Table 3 reports (for households holding either bonds or stocks) the portfolio shares for money $\left(\alpha_{m}\right)$, bonds $\left(\alpha_{b}\right)$ and stocks $\left(\alpha_{s}\right)$ for the five age groups. The life-cycle profiles in Table 3 do not show any substantial variations, even though there is a small tendency for the share of wealth in money balances to decrease over the working life 
Life Cycle Financial Wealth Accumulation Relative to Mean Labor Income

\begin{tabular}{lll}
\hline \hline Age Group & $\begin{array}{l}\text { Mean Wealth / Mean Income } \\
\text { No Bonds/Stocks }\end{array}$ & $\begin{array}{l}\text { Mean Wealth/Income } \\
\text { With either bonds or stocks }\end{array}$ \\
\hline $20-34$ & 0.07 & 1.37 \\
$35-45$ & 0.11 & 1.85 \\
$46-55$ & 0.13 & 3.51 \\
$56-65$ & 0.18 & 6.45 \\
$66-75$ & 0.60 & 11.9 \\
\hline
\end{tabular}

Table 2: Mean financial wealth relative to mean labor income for the two main groups (bond/stockholders and households with only a transaction account) from the $2001 \mathrm{SCF}$ data. The definitions for the different variables are in Appendix A

\begin{tabular}{llll}
\multicolumn{4}{l}{ Life Cycle Portfolio Choice } \\
\hline \hline Age Group & $\alpha_{m}$ & $\alpha_{b}$ & $\alpha_{s}$ \\
\hline $20-34$ & 27.7 & 33.2 & 39.1 \\
$35-45$ & 21.6 & 36.0 & 42.4 \\
$46-55$ & 18.9 & 41.3 & 39.8 \\
$56-65$ & 18.6 & 41.7 & 39.7 \\
$66-75$ & 25.0 & 48.0 & 27.0 \\
\hline
\end{tabular}

Table 3: Mean shares of financial wealth allocated to money, bonds and stocks from the $2001 \mathrm{SCF}$ data. The precise definitions for the different variables are in Appendix A.

cycle and increase after retirement.

We next sort the asset allocation decisions by age group and total financial wealth and report the results in table 4 .

Table 4 illustrates how less wealthy households tend to allocate a larger fraction of their wealth in liquid balances and reduce this dependence as they get wealhier. For every age group the share of financial wealth allocated to liquid balances decreases as the household gets wealthier. This decrease is primarily taken up by an increase in the share of wealth allocated to stocks since the share of wealth allocated to bonds tends to be more balanced and exhibits fewer changes. This stylized fact is a priori inconsistent with recent models of household portfolio choice, as pointed out by Wachter and Yogo (2009). 
Life Cycle Portfolio Choice by Age and Financial Wealth

\begin{tabular}{llll}
\hline \hline Age Group and Financial Wealth quartile & $\alpha_{m}$ & $\alpha_{b}$ & $\alpha_{s}$ \\
\hline 20-34 and One & 35.5 & 30.0 & 34.5 \\
20-34 and Two & 25.3 & 35.1 & 39.6 \\
20-34 and Three & 15.6 & 36.5 & 47.9 \\
20-34 and Four & 10.7 & 40.6 & 48.7 \\
35-44 and One & 33.3 & 42.5 & 24.2 \\
35-44 and Two & 21.9 & 40.7 & 37.4 \\
35-44 and Three & 16.3 & 30.6 & 53.1 \\
35-44 and Four & 12.4 & 27.9 & 59.7 \\
45-54 and One & 34.5 & 46.0 & 19.5 \\
45-54 and Two & 23.0 & 46.7 & 30.3 \\
45-54 and Three & 14.2 & 44.6 & 41.2 \\
45-54 and Four & 10.7 & 31.2 & 58.1 \\
55-64 and One & 31.0 & 56.4 & 12.6 \\
55-64 and Two & 23.3 & 44.2 & 32.5 \\
55-64 and Three & 19.0 & 37.1 & 43.9 \\
55-64 and Three & 10.2 & 36.8 & 53.0 \\
65 plus and One & 43.0 & 52.5 & 4.5 \\
65 plus and Two & 34.8 & 57.0 & 8.2 \\
65 plus and Three & 21.9 & 56.8 & 21.3 \\
65 plus and Four & 13.9 & 34.1 & 52.0 \\
\hline
\end{tabular}

Table 4: Mean shares of financial wealth allocated to money, bonds and stocks from the $2001 \mathrm{SCF}$ data. The portfolio choice decision is sorted by the four quartiles of financial wealth and the five age groups. The definitions for the variables can be found in Appendix A. 
In recent models of household portfolio choice the young tend to be endowed with high human capital and to the extent that this is not correlated with the stock market the prediction is that younger households should be more heavily invested in the stock market. As they grow older (and financially richer), the share of wealth in stocks should decrease. Wachter and Yogo (2009) rely on explaining these facts through a clever use of the utility function and preferences across goods. We will argue that the recent household portfolio choice models lump together money and bonds. Arguably money as a transaction vehicle might behave differently from the choice of a bond and therefore this assumption might not be innocuous. To do so one will need to build a motive for holding money, which is the approach we take in constructing our model in the next section.

These facts need to be explained in a model that includes inflation if one is to understand the effects of inflation on life cycle asset allocation. This is what we do next.

\section{The Model}

The model is a nominal version of life-cycle models that are extensively used in the household portfolio literature. Agents work while they are young, and receive a pension after retirement. They are subject to uninsurable labor income risk and borrowing constraints. There are three assets in the economy, money, bonds and stocks, and they are traded in nominal terms. In order to introduce money, we extend the model by introducing nominal assets and transaction frictions. 


\subsection{Preferences}

Time is discrete and $t$ denotes adult age which, following the typical convention in the literature, corresponds to effective age minus 19. Each period corresponds to one year and agents live for a maximum of $81(T)$ periods (age 100). The probability that a consumer/investor is alive at time $(t+1)$ conditional on being alive at time $t$ is denoted by $p_{t}\left(p_{0}=1\right)$. Finally, the consumer/investor has bequest motive.

Households have Epstein-Zin-Weil utility functions (Epstein and Zin (1989), Weil (1990)) defined over one single non-durable consumption good. Let $C_{i, t}$ and $X_{i, t}$ denote respectively consumption level and wealth (cash on hand) of agent $i$ at time $t$. The preferences of household $i$ are defined by

$$
V_{i, t}=\left\{(1-\beta) C_{i, t}^{1-1 / \psi}+\beta\left(E_{t}\left[p_{t} V_{i, t+1}^{1-\rho}+\left(1-p_{t}\right) b X_{i, t+1}^{1-\rho}\right]\right)^{\frac{1-1 / \psi}{1-\rho}}\right\}^{\frac{1}{1-1 / \psi}}
$$

where $\rho$ is the coefficient of relative risk aversion, $\psi$ is the elasticity of intertemporal substitution, $\beta$ is the discount factor, and $b$ determines the strength of the bequest motive.

\subsection{Labor Income Process}

Following the standard specification in the literature, the labor income process before retirement is given by

$$
\begin{gathered}
Y_{i, t}=Y_{i, t}^{p} U_{i, t} \\
Y_{i, t}^{p}=\exp \left(f\left(t, Z_{i, t}\right)\right) Y_{i, t-1}^{p} N_{i, t}
\end{gathered}
$$


where $f\left(t, Z_{i, t}\right)$ is a deterministic function of age and household characteristics $Z_{i, t}, Y_{i, t}^{p}$ is a permanent component with innovation $N_{i, t}$, and $U_{i, t}$ a transitory component. We assume that $\ln U_{i, t}$ and $\ln N_{i, t}$ are independent and identically distributed with mean $\left\{-.5 * \sigma_{u}^{2},-.5 * \sigma_{n}^{2}\right\}$, and variances $\sigma_{u}^{2}$ and $\sigma_{n}^{2}$, respectively. The $\log$ of $Y_{i, t}^{p}$ evolves as a random walk with a deterministic drift, $f\left(t, Z_{i, t}\right)$. For simplicity, retirement is assumed to be exogenous and deterministic, with all households retiring in time period $K$, corresponding to age 65 $(K=46)$. Earnings in retirement $(t>K)$ are given by $Y_{i, t}=\lambda Y_{i, K}^{p}$, where $\lambda$ is the replacement ratio (a scalar between zero and one).

Due to the absence of empirical studies at the micro level that estimate separate processes for stockholders and non-stockholders, we use the fact (surveyed for instance in Campbell (2006)) that financial wealth is correlated with stock market participation and education is correlated with both. We therefore use a different labor income parametrization depending on the household's education. We provide further details in the calibration section.

\subsection{Financial Assets and constraints}

The agent has options to hold three kinds of assets: fiat money $\left(M_{i, t}\right)$, nominal bonds $\left(B_{i, t}\right)$ and nominal stocks $\left(S_{i, t}\right)$. As in the standard literature, let $X_{i, t}$ be nominal "cash on hand" that the agent can use for consumption and portfolio decisions. The budget constraint is given by

$$
X_{i, t}=P_{t} C_{i, t}+S_{i, t}+B_{i, t}+M_{i, t}
$$

In order to motivate money holdings, we assume transaction frictions. Our approach is related to shopping time models, first proposed by McCallum and Goodfriend (1987), but we modify them to more easily incorporate in the port- 
folio choice literature. In shopping time models, transaction costs are modeled in terms of foregone time: money can help reduce transaction time. As is shown in Lucas (2000), there is a connection between the shopping time models and the inventory-theoretic studies of money (Baumol (1952), Tobin (1956)). ${ }^{5}$ More broadly speaking, the transaction cost can include not only a shopping cost but also a cost of selling illiquid assets to finance consumption. Different versions assume different trade-offs in the presence of transactions frictions. For example, Lucas (2000) assumes that agents face a trade-off between hours spent on production and transactions. Ljungqvist and Sargent (2004) (Ch. 24) assume a trade-off between transaction time and leisure. In this paper, we model transaction costs as a direct physical cost in terms of consumption goods. An advantage of our approach is that we can treat money by exactly the same way as we treat bonds and stocks because there is no additional margin between money holding decisions and leisure (or labor supply) decisions. Therefore our model maintains the basic structure of the models used in the portfolio choice literature, making the model computationally tractable and making its results easily comparable to those obtained in the literature. Also, our modeling approach maintains the basic properties of the shopping time models - money demand will be increasing in consumption and decreasing in nominal interest rates.

Let $H_{i, t}$ denote the transaction cost in terms of consumption goods associated with consumption expenditure at time $t$. We assume that this cost is deducted at the beginning of the next period. This timing assumption ensures that $X_{i, t}$ is a state variable, as in the portfolio choice literature. Then, the

\footnotetext{
${ }^{5}$ See Alvarez and Lippi (2009) for recent developments.
} 
evolution of $X_{i, t}$ is given by

$$
X_{i, t+1}=R_{t+1}^{s} S_{i, t}+R_{t+1}^{b} B_{i, t}+M_{i, t}+P_{t+1} Y_{i, t+1}-P_{t+1} H_{i, t}
$$

where $R_{t+1}^{s}$ and $R_{t+1}^{b}$ respectively denote the nominal returns of stocks and bonds. Note that the nominal return of fiat money is unity. Finally, $Y_{i, t+1}$ is real income at time $t+1$ that is discussed in Section 3.2.

We assume that transaction cost function is given by

$$
H_{i, t}=H\left(C_{i, t}, Z_{i, t} ; \xi_{i, t}\right), \quad H_{c}>0, \quad H_{z}<0
$$

where $Z_{i, t}$ represents the "liquid" part of household cash on hand, and $\xi_{i, t}$ is a vector of exogenous variables that affect the cost. We assume that $H_{i, t}$ is homogeneous of degree one. This assumption ensures that the size of the shopping cost relative to the household's consumption does not go zero as the households accumulate financial wealth. As in the standard monetary literature, $Z_{i, t}$ includes fiat money. We assume that $Z_{i, t}$ also includes labor income $Y_{i, t}$. The underlying assumption is that wage income is paid in terms of money, therefore labor income is as liquid as fiat money. Therefore, we assume that $Z_{i, t}$ is given by

$$
Z_{i, t}=M_{i, t-1}+P_{t} Y_{i, t}-P_{t} H_{i, t}
$$

This assumption allows agents with lower income and wealth to choose to be "hand-to-mouth", that is, $C_{i, t}=Y_{i, t}-H_{i, t-1}$, in line with the liquidity constraints literature initiated by Carroll (1997) and Deaton (1991). ${ }^{6}$ Further-

\footnotetext{
${ }^{6}$ If we just assume $Z_{i, t}=M_{i, t-1}$ as in the standard monetary literature, agents will need to carry over a positive amount of money from the previous period in order to consume this period. This implies that money holdings cannot be zero if agents want to consume.
} 
more, we assume that

$$
Y-H(Y-H, Y-H ; \xi)>0 .
$$

This assumption ensures that $X_{i, t} \geq 0$ at all times for realistic parameterizations of the volatility of the labor income process and that consumption is positive at all times. This assumption is not restrictive. Intuitively, (8) says that when the agent is hand-to-mouth, the transaction cost is always smaller than his/her labor income.

Finally, as in the portfolio choice literature, we prevent households from borrowing against their future labor income. More specifically we impose the following restrictions:

$$
\begin{gathered}
B_{i, t} \geq 0 \\
S_{i, t} \geq 0 \\
M_{i, t} \geq 0
\end{gathered}
$$

We have two state variables: $X_{i, t}$ and $Z_{i, t}$, and the control variables are $C_{i, t}$, $M_{i, t}, S_{i, t}$ and $B_{i, t}$.

\subsection{Specification of transaction technology}

In the benchmark simulation we assume that

$$
H_{i, t}=\varepsilon Y_{i, t}^{p} \frac{C_{i, t}}{Z_{i, t}}, \quad \varepsilon>0
$$

In this case, $h_{i, t}$ is given by

$$
h_{i, t}=\varepsilon \frac{c_{i, t}}{z_{i, t}}, \quad \varepsilon>0 .
$$


Our preferred interpretation is that the transaction cost represents an opportunity cost of time and is therefore proportional to the permanent component of labor income. The opportunity cost maps into monetary units as specified in (9). Parameter $\varepsilon$ measures the severity of transaction frictions. A large $\varepsilon$ means it takes more resources to do transactions and it can be different over the life cycle or across agents. For example, older people may have more spare time to undertake transactions, therefore having a smaller $\varepsilon$ compared with the young. Another example might be educated households that have better ability to manage nonmonetary assets, also having a smaller $\varepsilon$.

Another functional form for $H_{i, t}$ is to assume that

$$
H_{i, t}=\varepsilon C_{i, t}^{\gamma} Z_{i, t}^{1-\gamma}, \quad \gamma>1
$$

In this case, we obtain

$$
h_{i, t}=\varepsilon c_{i, t}^{\gamma} z_{i, t}^{1-\gamma}
$$

This avoids the opportunity cost of time interpretation but adds an additional parameter to the model. For simplicity, we perform our estimations based on (9). ${ }^{7}$

\subsection{Specification of aggregate exogenous processes}

We will use exogenous processes for stock and bond returns, inflation and the aggregate component of labor income. Given that we calibrate the cross sectional model to decisions taken in 2001, we use the period 1995 to 2008 to compute descriptive statistics and correlations between these variables and provide comparative statics experiments later on based on historical experi-

\footnotetext{
${ }^{7}$ The functional form (9) is also consistent with Lucas (2000) who shows that the implied money demand function is consistent with the demand function of Baumol (1952) and Tobin (1956).
} 
ence.

\subsection{Participation cost}

Before participating into nonmonetary asset markets for the first time, the investor must pay a fixed lump sum cost, $F * Y_{i, t}^{p}$. This entry fee represents both the explicit transaction cost from opening a brokerage account and the (opportunity) cost of acquiring information about the stock market. The fixed cost $(F)$ is scaled by the level of the permanent component of labor income $\left(Y_{i, t}^{p}\right)$ as this simplifies significantly the solution of the model. However, this specification is also motivated by the interpretation of the entry fee as the opportunity cost of time. We define a dummy variable $I_{P}$ which is equal to one when the fixed entry cost is incurred for the first time and zero otherwise.

\subsection{Normalizing by Prices and Growth}

Let lower case letters denote real variables normalized by the permanent component of labor income $\left(Y_{i, t}^{p}\right)$. For example normalised real cash on hand is defined as $x_{i, t}=X_{i, t} /\left(Y_{i, t}^{p} P_{t}\right)$. Similarly, normalized transaction cost is $h_{i, t} \equiv H_{i, t} / Y_{i, t}^{p}$ and so on. The evolution of the state variables is given by

$$
x_{i, t+1}=\frac{r_{t+1}^{s}}{g_{i, t+1}} s_{i, t}+\frac{r_{t+1}^{b}}{g_{i, t+1}} b_{i, t}+\frac{r_{t+1}^{m}}{g_{i, t+1}} m_{i, t}+y_{i, t+1}-\frac{h_{i, t}}{g_{i, t+1}}
$$

where

$$
r_{t+1}^{s} \equiv R_{t+1}^{s} \pi_{t+1}^{-1}, \quad r_{t+1}^{b} \equiv R_{t+1}^{b} \pi_{t+1}^{-1}, \quad r_{t+1}^{m} \equiv \pi_{t+1}^{-1}
$$

are respectively the real returns of stocks, nominal bonds and money, where $\pi_{t+1} \equiv P_{t+1} / P_{t}$ denotes gross inflation, and $g_{i, t+1} \equiv Y_{i, t+1}^{p} / Y_{i, t}^{p}$ is the gross 
growth rate of permanent income. Similarly, $z_{i, t}$ evolves according to

$$
z_{i, t+1}=\frac{r_{t+1}^{m}}{g_{i, t+1}} m_{i, t}+y_{i, t+1}-\frac{h_{i, t}}{g_{i, t+1}}
$$

\subsection{Normalised recursive utility}

Let $v_{i, t} \equiv V_{i, t} / Y_{i, t}^{p}$ be normalised value, and $g_{i, t+1} \equiv Y_{i, t+1}^{p} / Y_{i, t}^{p}$. Then, by dividing both sides of equation (1) by $Y_{i, t}^{p}$, we obtain

$$
\begin{aligned}
v_{i, t}= & {\left[(1-\beta) c_{i, t}^{1-1 / \psi}\right.} \\
& \left.+\beta\left\{E_{t}\left[p_{t}\left(v_{i, t+1}\right)^{1-\rho}\left(Y_{i, t+1}^{p} / Y_{i, t}^{p}\right)^{1-\rho}+\left(1-p_{t}\right) b \frac{\left(x_{i, t+1}\right)^{1-\rho}\left(Y_{i, t+1}^{p} / Y_{i, t}^{p}\right)^{1-\rho}}{1-\rho}\right]\right\}^{\frac{1-1 / \psi}{1-\rho}}\right]^{\frac{1}{1-1 / \psi}} \\
= & {\left[(1-\beta) c_{i, t}^{1-1 / \psi}+\beta\left\{E_{t}\left[p_{t}\left(v_{i, t+1} g_{i, t+1}\right)^{1-\rho}+\left(1-p_{t}\right) b \frac{\left(x_{i, t+1} g_{i, t+1}\right)^{1-\rho}}{1-\rho}\right]\right\}^{\frac{1-1 / \psi}{1-\rho}}\right]^{\frac{1}{1-1 / \psi}} . }
\end{aligned}
$$

The two states are $x_{i, t}$ and $z_{i, t}$ and their evolutions are given by (13) and (14).

\section{Parameter Estimation}

We will estimate the preference parameters separately for the two main groups we have identified: the rich and the poor households. We do this separately relying on preference heterogeneity to generate the large variation in outcomes. The idea is that poor households will not have an incentive to participate in the bond and stock market in the presence of a fixed cost if they have not managed to accumulate a reasonable amount of financial wealth.

Given the large number of parameters in the model we will calibrate certain parameters and then estimate the preference and shopping cost parameters. 


\begin{tabular}{lll}
\multicolumn{3}{l}{ Means and Standard Deviations } \\
\hline \hline Variable & Mean & Standard Deviation \\
\hline Inflation & 2.5 & 1.0 \\
Bond Returns & 2.4 & 2.6 \\
Stock Returns & 6.8 & 22.0 \\
Wage growth & 2.7 & 2.0 \\
\hline
\end{tabular}

Table 5: We report the means and standard deviations of key inputs in the decision model. All variables are real, and the bond return is the return on the one-year bond. Details about the data can be found in Appendix A.

The calibration for labor income uses the estimates in Cocco (2005) so that $\sigma_{u}=0.1, \sigma_{n}=0.08$, and $\lambda=0.68$. For the poorer households we use the hump shape process estimated for high school graduates while for the richer households we use the hump shape process for households with a college degree.

We use annual CRSP data for the U.S. from 1926 to 2008 for inflation, stock returns, long and short bond returns. Given that we estimate a cross sectional model based on 2001 SCF data we focus on the returns and correlations from 1995 to 2008 but provide extensive comparative statics with regards to the main parameters to reflect other historical episodes with different return characteristics. The table below reports the descriptive statistics for the variables of interest.

We also assume an i.i.d process for stock returns with a mean real return equal to six percent and a standard deviation equal to $18 \%$. The bond return process is similarly calibrated with a mean return equal to two percent and a standard deviation equal to three percent.

We also need to take a stance on the correlations across these variables. The correlations are set according to the following table from the 1995-2008 correlations in the data:

Based on this table, and for this period, we set the correlations between bond and stock returns equal to zero, as well as the correlation between infla- 
Correlation Matrix

\begin{tabular}{lllll}
\hline \hline Variable & Inflation & Bond Returns & Stock Returns & Wage Growth \\
\hline Inflation & 1.0 & -0.49 & 0.25 & -0.06 \\
Bond Returns & & 1.0 & -0.1 & 0.37 \\
Stock Returns & & & 1.0 & 0.44 \\
Wage growth & & & 1.0 \\
\hline
\end{tabular}

Table 6: We report the correlation matrix of key inputs in the decision model. All variables are real, and the bond return is the return on the one-year bond. This is for the period between 1995 and 2008. Details about the data can be found in Appendix A.

tion and the real wage growth.

To use the method of simulated moments we need to decide which moments to match. The key variables of interest for our purposes are the mean holdings of financial wealth over the life cycle and the asset allocations between money, bonds and stocks sorted by age and financial wealth. For the rich households that find it optimal to participate in all asset markets, we pick the structural parameters to minimize the distance between five moments of wealth from the simulated model and the same five moments reported in 2 . At the same time we sort financial portfolios for money, bonds and stocks by age and financial wealth and match the simulated data to the ones reported in 4 . This gives a total of forty five moment conditions. The structural parameters are $\left\{b, \psi, \rho, \varepsilon_{w}, \varepsilon_{r}\right\}$ where $\varepsilon_{w}$ denotes the shopping cost for workers and $\varepsilon_{r}$ the one for retirees. A similar process is used for the poor where now the only moments are the five financial wealth ones reported in 2 as they do not hold anything but money balances. $^{8}$

\footnotetext{
${ }^{8}$ We provide estimates of the structural parameters using Method of Simulated Moments Estimator (MSM) of ?. The structural parameters collected in a vector $\hat{\theta}$ are determined as:

$$
\hat{\theta}=\operatorname{Argmin}_{\theta} D^{\prime} S^{-1} D .
$$

Let $Y_{t}$ and $\tilde{Y}_{t}$ denote the observations at time $t$ of the actual and simulated endogenous variables, respectively. Let $T$ be the sample size of the observed series whereas $T \cdot H$ data points are simulated to compute moments from the structural model. For the latter, let $Y_{[T]}$ and $\tilde{Y}_{[T H]}$ denote the vectors of actual and simulated endogenous variables of length $T$ and
} 


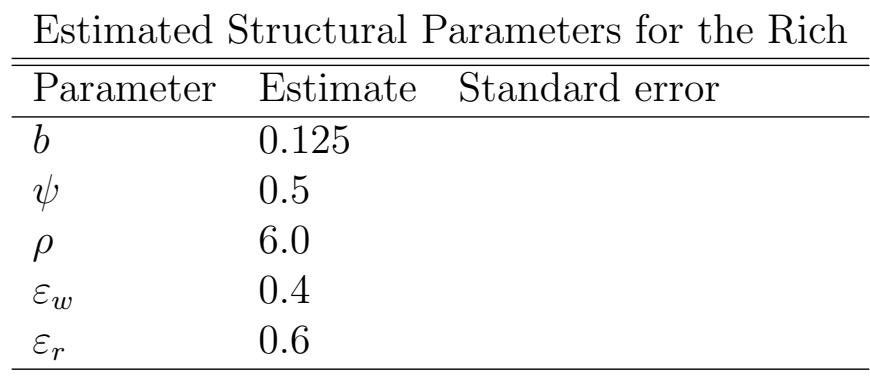

Table 7: Estimated structural parameters for the rich households.

\section{Results for the Rich}

The estimated parameters for the households that participate in at least one market other than the money market are given in table...

The results are consistent with previous estimates of preference parameters that exist in the literature. A relatively high risk aversion is needed to generate balanced portfolios between bonds and stocks given the high equity premium, while the EIS at 0.5 is consistent with the estimated parameters in VissingJorgensen (2002). There is some evidence for a bequest motive needed because financial wealth is not fully decumulated during retirement, while there are no micro estimates of the shopping cost parameters against which we can compare our results (this was also one of the reasons for performing structural estimation).

How do the predicted moments compare with the actual ones? We first go through the mean wealth to mean labor income ratios which are given in table...

$T H$, respectively. We have:

$$
D=\left(\frac{1}{T} \sum_{t=1}^{T} \operatorname{moments}\left(Y_{t}\right)-\frac{1}{T H} \sum_{t=1}^{T H} \operatorname{moments}\left(\tilde{Y}_{t}\right)\right) .
$$

where moments() denotes a particular moment. The asymptotically efficient optimal weighting matrix $S^{-1}$ equals the inverse of the variance-covariance matrix of the data. Following Appendix B in ?, we use a diagonal weighting matrix for $S^{-1}$ with the elements along the diagonals being the variance of each moment from the data. 
Predicted vs Actual Life Cycle Financial Wealth to Labor Income

\begin{tabular}{lll}
\hline \hline Age Group & $\begin{array}{l}\text { Mean Wealth/Mean Income } \\
\text { Data }\end{array}$ & $\begin{array}{l}\text { Mean Wealth/Mean Income } \\
\text { Predicted Moments }\end{array}$ \\
\hline $20-34$ & 1.37 & 1.86 \\
$35-45$ & 1.85 & 4.57 \\
$46-55$ & 3.51 & 8.38 \\
$56-65$ & 6.45 & 12.78 \\
$66-75$ & 11.9 & 19.76 \\
\hline
\end{tabular}

Table 8: Actual versus predicted moments for mean financial wealth relative to mean labor income for the bond/stockholders. The model is compared to the 2001 SCF data. The definitions for the different variables are in Appendix A

We observe that the model predicts some overaccumulation in wealth levels relative to the financial wealth present in the data. Partly this occurs because of the need to generate balanced portfolios but we have also kept the discount factor constant. A future version of the paper should attempt to include the discount factor as one of the parameters to be estimated before further discussion can be safely made.

We next present the moments for the portfolio shares.

The results illustrate the strong demand for stocks early in life as labor income is mostly seen like a riksless asset. Nevertheless, money is held in the portfolio for transaction purposes, thereby dramatically changing the composition of the portfolio relative to other models in the portfolio choice literature that lump money and bonds in the same category. Specifically, in these models the standard prediction is that stockholders should allocate all financial wealth in stockholding while in this setup the very young (ages 25-34) allocate between 65 to 80 percent of their financial wealth in stocks. The allocation to bonds is still underpredicted relative to the data but we view the model as getting one step closer to matching observed behavior in the data.

It should also be noted that the share of wealth allocated to stocks increases 
Predicted and Actual Moments

Actual Moments Predicted Moments

\begin{tabular}{lllllll}
\hline \hline Age Group and Financial Wealth quartile & $\alpha_{m}$ & $\alpha_{b}$ & $\alpha_{s}$ & $\widehat{\alpha}_{m}$ & $\widehat{\alpha}_{b}$ & $\widehat{\alpha}_{s}$ \\
\hline 20-34 and One & 35.5 & 30.0 & 34.5 & 34.9 & 0.0 & 65.1 \\
20-34 and Two & 25.3 & 35.1 & 39.6 & 39.5 & 0.0 & 60.5 \\
20-34 and Three & 15.6 & 36.5 & 47.9 & 24.4 & 0.0 & 75.6 \\
20-34 and Four & 10.7 & 40.6 & 48.7 & 20.1 & 0.0 & 79.9 \\
35-44 and One & 33.3 & 42.5 & 24.2 & 19.5 & 0.1 & 80.4 \\
35-44 and Two & 21.9 & 40.7 & 37.4 & 20.0 & 1.5 & 78.5 \\
35-44 and Three & 16.3 & 30.6 & 53.1 & 20.0 & 22.7 & 57.3 \\
35-44 and Four & 12.4 & 27.9 & 59.7 & 20.0 & 34.1 & 45.9 \\
45-54 and One & 34.5 & 46.0 & 19.5 & 20.0 & 39.5 & 40.5 \\
45-54 and Two & 23.0 & 46.7 & 30.3 & 18.5 & 41.7 & 39.8 \\
45-54 and Three & 14.2 & 44.6 & 41.2 & 19.2 & 45.2 & 35.6 \\
45-54 and Four & 10.7 & 31.2 & 58.1 & 20.0 & 57.8 & 22.2 \\
55-64 and One & 31.0 & 56.4 & 12.6 & 20.0 & 51.2 & 28.8 \\
55-64 and Two & 23.3 & 44.2 & 32.5 & 19.7 & 59.5 & 20.8 \\
55-64 and Three & 19.0 & 37.1 & 43.9 & 16.7 & 63.3 & 20.0 \\
55-64 and Four & 10.2 & 36.8 & 53.0 & 19.6 & 60.4 & 20.0 \\
65 plus and One & 43.0 & 52.5 & 4.5 & 35.7 & 44.2 & 20.1 \\
65 plus and Two & 34.8 & 57.0 & 8.2 & 28.4 & 50.2 & 21.4 \\
65 plus and Three & 21.9 & 56.8 & 21.3 & 20.5 & 58.5 & 21.0 \\
65 plus and Four & 13.9 & 34.1 & 52.0 & 20.0 & 60.5 & 19.5 \\
\hline
\end{tabular}

Table 9: Predicted versus Actual mean shares of financial wealth allocated to money, bonds and stocks. Data are from the 2001 SCF. The portfolio choice decision is sorted by the four quartiles of financial wealth and the five age groups. The definitions for the variables can be found in Appendix A. 
for the youngest age group as households get richer. This is in accordance with the data and therefore also needs to be better explained. (Compare to Wachter and Yogo paper).

\subsection{Comparative Statics}

\subsubsection{No money $\varepsilon_{w}=\varepsilon_{r}=0$}

To understand the predictions of the model better, we next perform a series of comparative statics. The first model we can compare our results to is the standard portfolio choice model where money does not circulate. In our model this specification is nested by setting the shopping technology parameters equal to zero. Figures 1 and 2 respectively show the prediction of the model in the benchmark case and the case in which the shopping parameter $\varepsilon$ is set to zero. This is an interesting case because money does not circulate in this economy and the model becomes identical with the recent models on household portfolio choice like Cocco (2005) or Gomes and Michaelides (2005). We can see that these models generate a large demand for stocks early in life because future labor income is treated like a bond. The shopping technology on the other hand generates a demand for money that can generate an upward sloping share of wealth in stocks over the early years of the lifecycle.

Recently Wachter and Yogo (2009) have argued that non-separabilities in the utility function across different goods can generate the upward sloping shape for the share of wealth in stocks as financial wealth increases. Our model provides an alternative explanation that relies on the determinants of money demand. 


\subsubsection{Higher mean inflation}

Figure 3 shows the results when mean inflation is higher by 5 percentage points. A high mean inflation decreases the mean rate of return of holding money, and as a result, households reduce money holdings, which is in line with the money demand literature. However, in contrast to the literature, the young and old households substitute money for different kinds of assets.

The younger households hedge inflation by investing in stocks rather than bonds. Figure 3 shows that the young household' money holding drops to zero. However, note that we assume that labor income is paid in terms of money. Therefore zero money holdings do not necessarily imply that the young households do not have money at all. Rather, it shows that they do not use money as a store of value when they make their portfolio decision.

In contrast, the older households' pension income is not very high compared with their consumption stream. In this case, they choose to hold money in their portfolio in order to reduce shopping costs. However, in contrast to the young and in the traditional literature, they substitute money for bonds when inflation is higher.

Since all the households economize money holdings, they are paying high transaction costs. This reduces life-time income, reducing consumption over the entire life cycle.

\subsubsection{Hedging Demands}

In order to analyze how inflation affects portfolio choice through its correlations with other asset returns, Figure 4 shows the hypothetical case in which inflation is uncorrelated with the other shocks, but still keep the other correlations as in the data. More specifically, it is assumed that the correlation between inflation and stock returns and that between inflation and bond returns are 


\begin{tabular}{|c|c|}
\hline Parameter & Estimate $\quad$ Standard error \\
\hline$b$ & 0.17 \\
\hline$\psi$ & 0.03 \\
\hline$\rho$ & 1.44 \\
\hline$\varepsilon_{w}$ & 0.75 \\
\hline$\varepsilon_{r}$ & 1.3 \\
\hline
\end{tabular}

Table 10: Estimated structural parameters for the poor households.

zero. ${ }^{9}$ Compared with the benchmark case, the households invest more in stocks particularly in the early stage of their life cycle. In the benchmark case (i.e., in data), inflation and stock return are positively correlated, which implies that the rate of return of money and stocks are negatively correlated. Therefore, there is hedging demand for money against stocks. This hedging demand for money is another factor that dampens the portfolio share of stocks.

It is shown in the portfolio literature that a positive correlation between labor income and stock returns can reduce the share of stocks (citation needed). In order to check this, we also examined the case in which all shocks are uncorrelated. Figure 5 shows that removing correlation between labor income and stock returns (in addition to removing correlation of inflation) has only marginal effect (Need to understand why). Therefore the dampened share of stocks in our model is mainly driven by the correlation of inflation with stock return.

\section{Results for the Poor}

The estimated parameters for the households that participate only in the money market are given in table...

The results are consistent with previous estimates of preference parameters

\footnotetext{
${ }^{9}$ Data shows that inflation and real income growth is uncorrelated, so this correlation is kept equal to zero.
} 
Predicted vs Actual Life Cycle Financial Wealth to Labor Income

\begin{tabular}{lll}
\hline \hline Age Group & $\begin{array}{l}\text { Mean Wealth/Mean Income } \\
\text { Data }\end{array}$ & $\begin{array}{l}\text { Mean Wealth/Mean Income } \\
\text { Predicted Moments }\end{array}$ \\
\hline $20-34$ & 0.07 & 0.03 \\
$35-45$ & 0.11 & 0.05 \\
$46-55$ & 0.13 & 0.11 \\
$56-65$ & 0.18 & 0.38 \\
$66-75$ & 0.60 & 0.43 \\
\hline 75 plus & 0.55 & 0.45 \\
\hline
\end{tabular}

Table 11: Actual versus predicted moments for mean financial wealth relative to mean labor income for the poor households. The model is compared to the 2001 SCF data. The definitions for the different variables are in Appendix A

that exist in the literature. A relatively low risk aversion and elasticity of intertemporal substitution is needed to generate low wealth accumulation as in Vissing-Jorgensen (2002) and in Gomes and Michaelides (2005). There is some evidence for a bequest motive for the poor households and the shopping parameters are needed as these households only hold liquid money balances.

How do the predicted moments compare with the actual ones? We first go through the mean wealth to mean labor income ratios which are given in table...

The profiles are consistent with the idea that these households accumulate small amounts of financial wealth and therefore have a weak incentive pay a fixed costs to enter the stock and bond market.

Estimate of $\varepsilon$ too large.... Figure 6 shows that the old households are paying a significant fraction of their pension on shopping cost. (pension is 1 but consumption is about 0.6 ). This is to be fixed.

Figure 7 (without shopping cost) looks fine.

Figure 8 shows that a higher mean inflation increases saving even though the rate of return of money becomes lower. What is the intuition behind this?? (If we remove shopping costs, then a higher inflation reduces saving, which is 
more intuitive. )

\section{Implications for Money Demand}

What is the partial equilibrium relationship between money demand and the nominal interest rate on bonds? Solve both models for different interest rates, and plot money demand from the poor, the rich and the aggregate part. Maybe plot aggregate consumption? Does portfolio choice change as inflation changes? Any nonlinearities as the nominal interest rate approaches zero?

\section{Conclusion}

We have estimated the preference parameters of a life cycle money demand and portfolio choice model. The predictions of the model are consistent with the data and the model can be therefore used to analyze how inflation or deflation affects money demand and asset allocation. Future work can extend the analysis in a general equilibrium setting.

\section{Appendix A The Data}

\section{A.1 Survey of Consumer Finances}

We use repeated cross sections from the U.S. Survey of Consumer Finances to establish certain robust facts with regards to household choices across liquid accounts (money), bonds and stocks. Total financial assets are broken up into the three broad categories the model has implications for: liquid resources (LIQ), stock (EQUITY) and nonequity (BOND) investments. In the 2001 public extract of the SCF data set, LIQ is defined as the sum of all checking, saving, 
money market deposit and call accounts. We follow the same convention and LIQ becomes our measure of money when confronting the model implications to the data. EQUITY is defined in the same extract as all financial assets invested in stocks and this comprises the following categories:

1) directly held stock

2) stock mutual funds (the full value is assigned if the fund is described as a stock mutual fund, and half the value for combination mutual funds)

3) IRAs/Keoghs invested in stock (full value if mostly invested in stock, half value if split between stocks/bonds or stocks/money market, one third value if split between stocks/bonds/money market),

4) other managed assets with equity interest (annuities, trusts, MIAs) (where again the full value is used if mostly invested in stock, half value if split between stocks/MFs \& bonds/CDs, or "mixed/diversified," and one third value if "other")

5) thrift-type retirement accounts invested in stock (full value if mostly invested in stock and half value if split between stocks and interest earning assets) and

6) savings accounts classified as 529 or other accounts that may be invested in stocks. We classify the remaining financial assets as BOND and interpret them as capturing the bond investments in the model (both government and corporate bonds are lumped together in this category).

\section{A.2 Aggregate Data}

We used the CRSP data base to download annual US inflation, bond and stock returns from 1925 to 2008 . We report empirical results for long and short bond yields in the paper. More details.

For the aggregate component of labor income we use the NIPA wages and 
salary disbursement series and we deflate using the inflation rate from CRSP. 


\section{References}

Alvarez, Fernando and Francesco Lippi, "Financial Innovation and the Transactions Demand for Cash," Econometrica, 2009, 77 (2), 363-402.

Attanasio, Orazio, James Banks, Costas Meghir, and Guglielmo Weber, "Humps and bumps in lifetime consumption," Journal of Business \& Economic Statistics, 1999, 17 (1), 22-35.

Baumol, William J., "The transactions demand for cash: An inventory theoretic approach," The Quarterly Journal of Economics, 1952, 66 (4), $545-556$.

Cagetti, Marco, "Wealth Accumulation over the Life Cycle and Precautionary Savings.," Journal of Business 85 Economic Statistics, 2003, 21 (3), 339-354.

Campbell, John Y., "Household Finance," Journal of Finance, 2006, 61 (4), 1553-1604.

Carroll, Christopher D., "Buffer-Stock Saving and the Life Cycle/Permanent Income Hypothesis," Quarterly Journal of Economics, 1997, $112(1), 1-55$.

Castaneda, Ana, Javier Diaz-Gimenez, and Jose-Victor Rios-Rull, "Accounting for the U.S. Earnings and Wealth Inequality," Journal of Political Economy, 2003, 111 (4), 818-857.

Chatterjee, Satyajit and P. Dean Corbae, "Endogenous Market Participation and the General Equilibrium Value of Money," Journal of Political Economy, 1992, 100 (3), 615-46.

Christiano, Lawrence J., Martin Eichenbaum, and Charles L. Evans, "Nominal Rigidities and the Dynamic Effects of a Shock to Monetary Policy," Journal of Political Economy, 2005, 113 (1), 1-45.

Cocco, Joao F., "Portfolio Choice in the Presence of Housing," Review of Financial Studies, 2005, 18 (2), 535-567.

_, Francisco J. Gomes, and Pascal J. Maenhout, "Consumption and portfolio choice over the life cycle," Review of financial Studies, 2005, 18 (2), 491-533.

De Nardi, Mariacristina, "Wealth Inequality and Intergenerational Links," Review of Economic Studies, 2004, 71, 743-768.

Deaton, Angus, "Saving and liquidity constraints," Econometrica, 1991, 59 (5), 1221-1248. 
Doepke, Matthias and Martin Schneider, "Inflation and the Redistribution of Nominal Wealth," Journal of Political Economy, 2006, 114 (6), 1069-1097.

Epstein, Larry G. and Stanley E. Zin, "Substitution, risk aversion, and the temporal behavior of consumption and asset returns: A theoretical framework," Econometrica: Journal of the Econometric Society, 1989, pp. 937-969.

Erosa, Andres and Gustavo Jaime Ventura, "On inflation as a regressive consumption tax," Journal of Monetary Economics, 2002, 49 (4), 761-795.

Gomes, Francisco, Alexander Michaelides, and Valery Polkovnichenko, "Optimal Savings with Taxable and Tax-Deferred Accounts," Review of Economic Dynamics, 2009, 12 (4), 718-735.

_ and _, "Portfolio Choice With Internal Habit Formation: A Life-Cycle Model With Uninsurable Labor Income Risk," Review of Economic Dynamics, 2003, 6 (4), 729-766.

_ and _ , "Optimal Life-Cycle Asset Allocation: Understanding the Empirical Evidence," Journal of Finance, 2005, 60 (2), 869-904.

Gourinchas, Pierre-Olivier and Jonathan A. Parker, "Consumption Over the Life Cycle," Econometrica, 2002, 70 (1), 47-89.

Kiyotaki, Nobuhiro and Randall Wright, "On Money as a Medium of Exchange," Journal of Political Economy, 1989, 97 (4), 927-54.

Krusell, Per and Anthony A. Jr. Smith, "Income and Wealth Heterogeneity in the Macroeconomy," Journal of Political Economy, 1998, 106 (5), $867-896$.

Ljungqvist, Lars and Thomas J. Sargent, Recursive macroeconomic theory, The MIT Press, 2004.

Lucas, Robert E., "Inflation and Welfare," Econometrica, 2000, 68 (2), 247274.

- and Nancy Stokey, "Money and Interest in a Cash-in-Advance Economy," Econometrica, 1987, 55 (3), 491-513.

McCallum, Bennett T. and Marvin S. Goodfriend, "Demand for money: theoretical studies," The New Palgrave: A Dictionary of Economics, 1987, $1,775-81$.

Mulligan, Casey B. and Xavier Sala-i-Martin, "Extensive margins and the demand for money at low interest rates," Journal of Political Economy, 2000, 108 (5), 961-991. 
Polkovnichenko, Valery, "Life-Cycle Portfolio Choice with Additive Habit Formation Preferences and Uninsurable Labor Income Risk," Review of Financial Studies, 2007, 20 (1), 83-124.

Sidrauski, Muguel, "Rational choice and patterns of growth in a monetary economy," The American Economic Review, 1967, 57 (2), 534-544.

Tobin, James, "The interest-elasticity of transactions demand for cash," The Review of Economics and Statistics, 1956, 38 (3), 241-247.

Vissing-Jorgensen, Annette, "Limited Asset Market Participation and the Elasticity of Intertemporal Substitution," Journal of Political Economy, $2002,110(4), 825-853$.

Wachter, Jessica and Motohiro Yogo, "Why Do Household Portfolio Shares Rise in Wealth?," Working paper, Wharton School of Business, 2009.

Weil, Philippe, "Nonexpected Utility in Macroeconomics," The Quarterly Journal of Economics, 1990, 105 (1), 29-42. 
Figure 1-1. Stockholders

mean consumption, wealth, and income: benchmark case
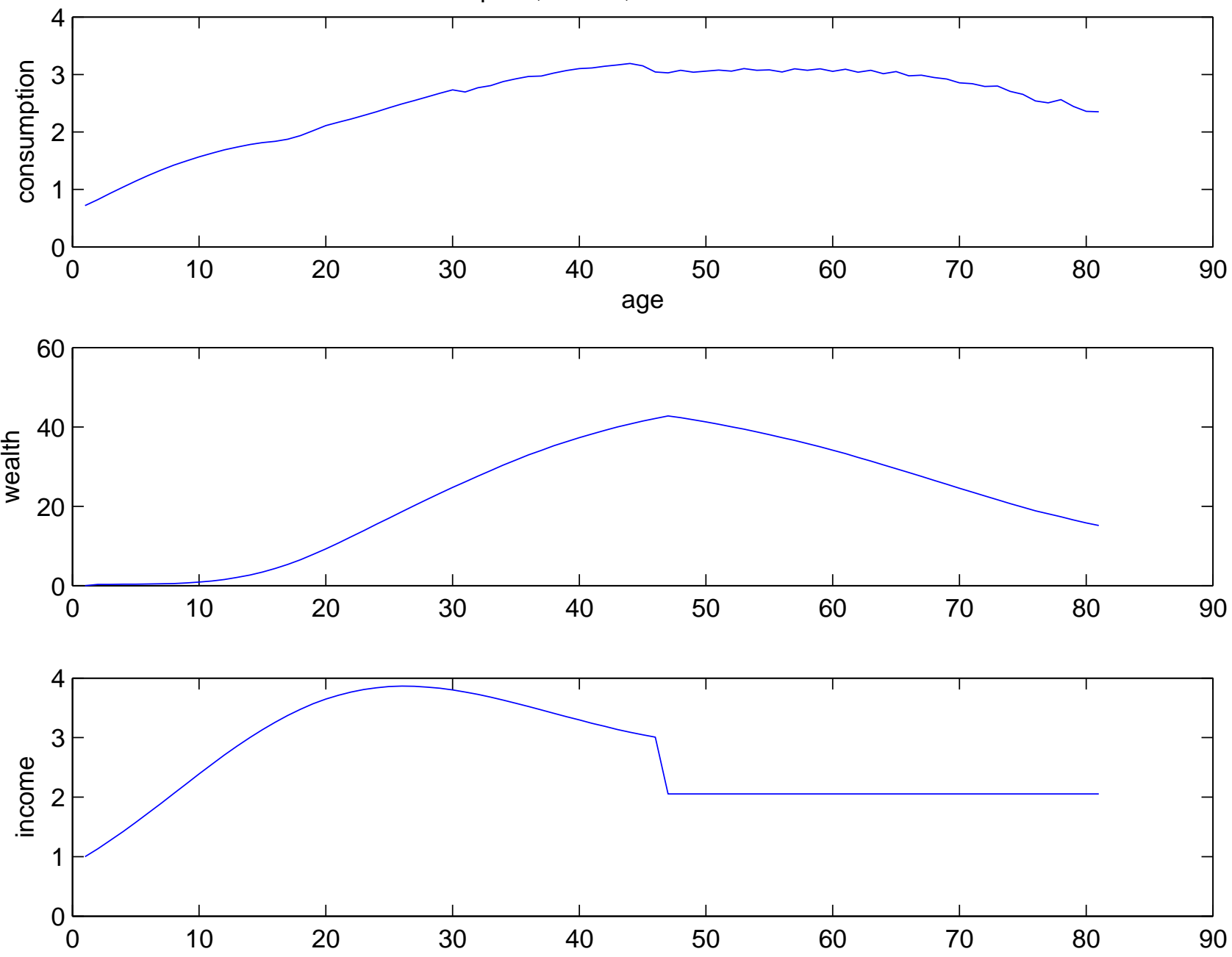
Figure 1-2. Stockholders

mean portfolio: benchmark case
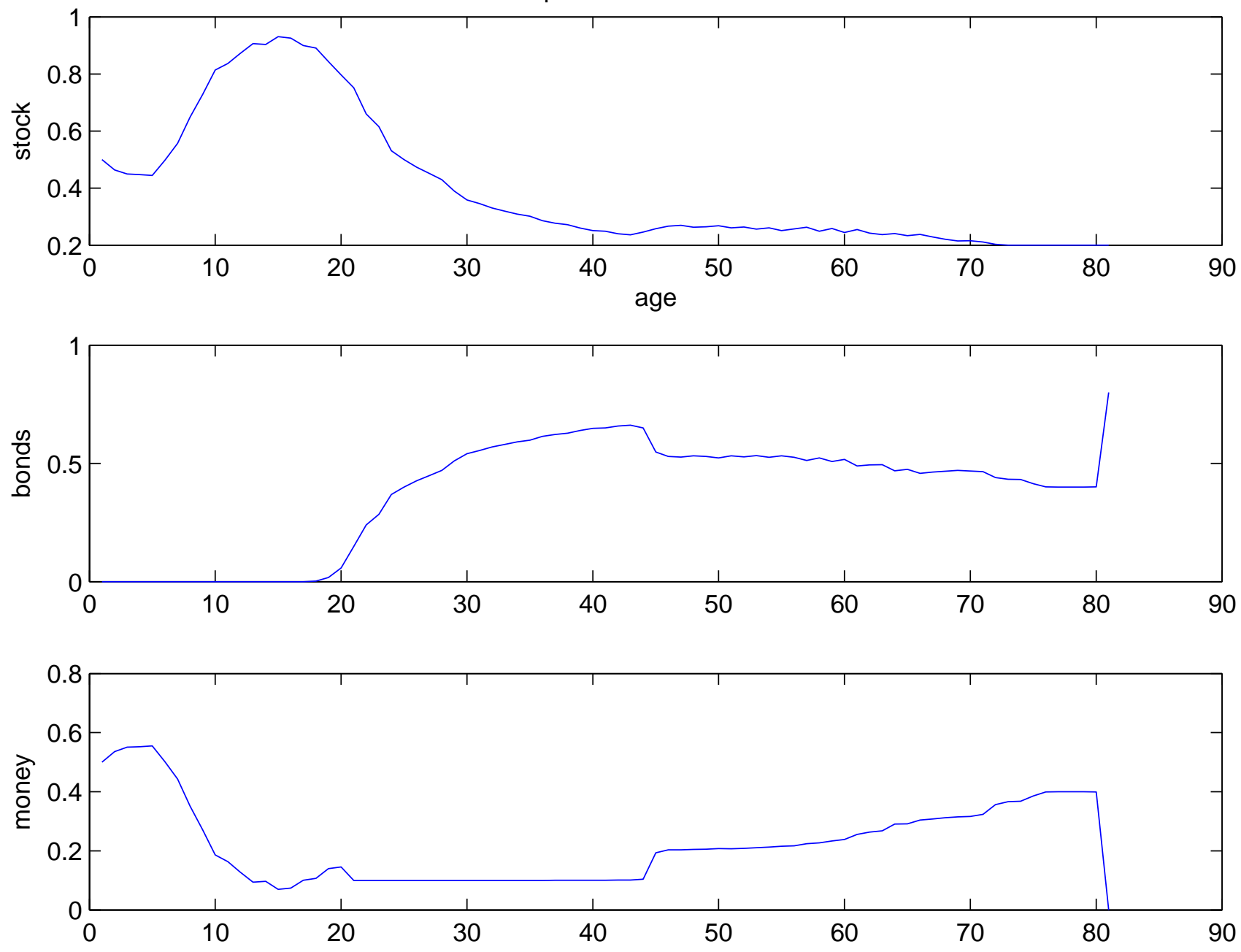
Figure 1-3. Stockholders
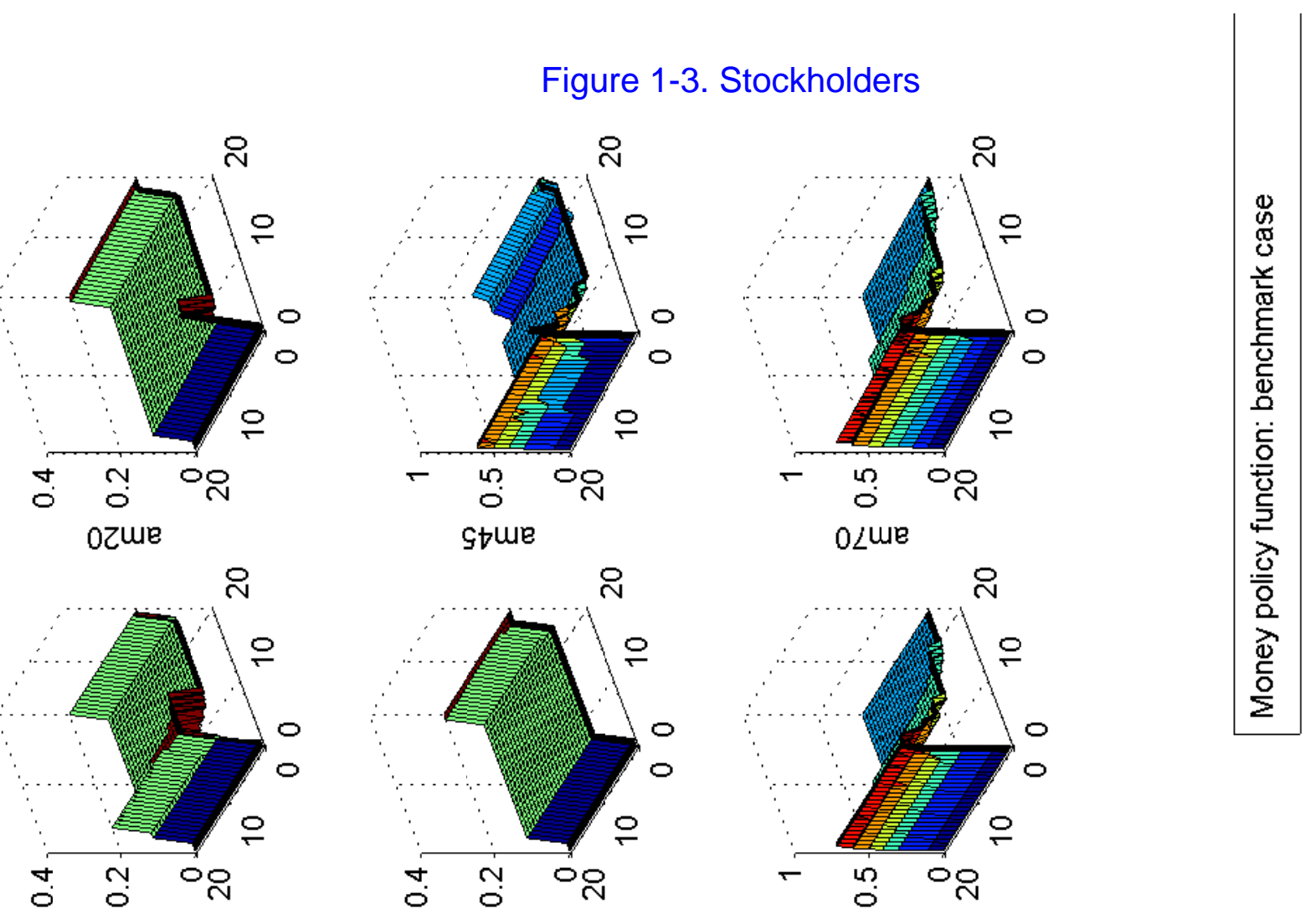

sture

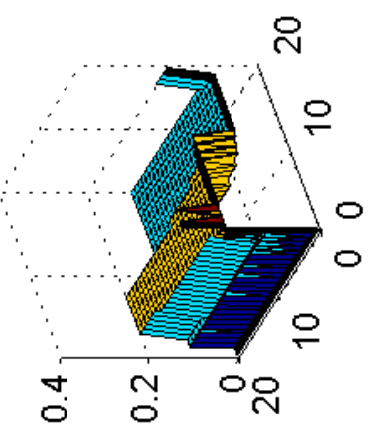

olure

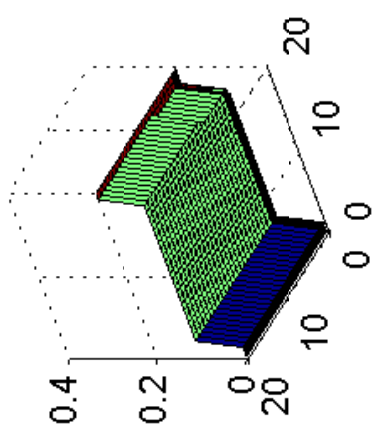

seure

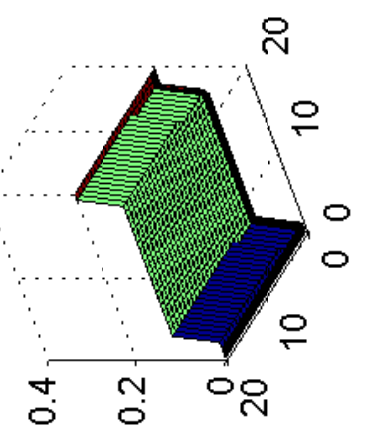

ocure
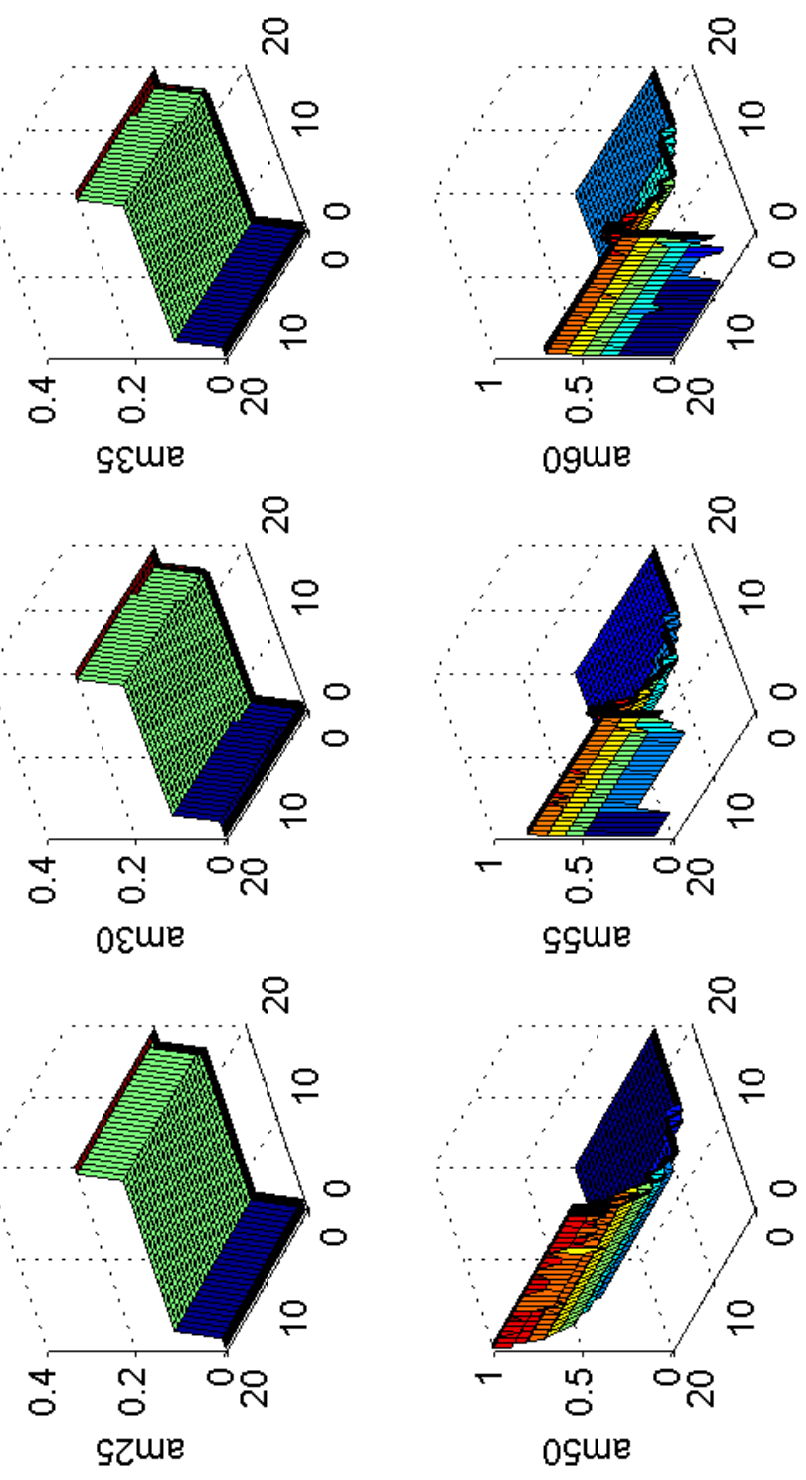

ogure

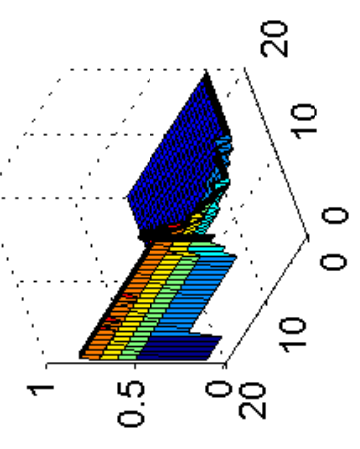

sçue
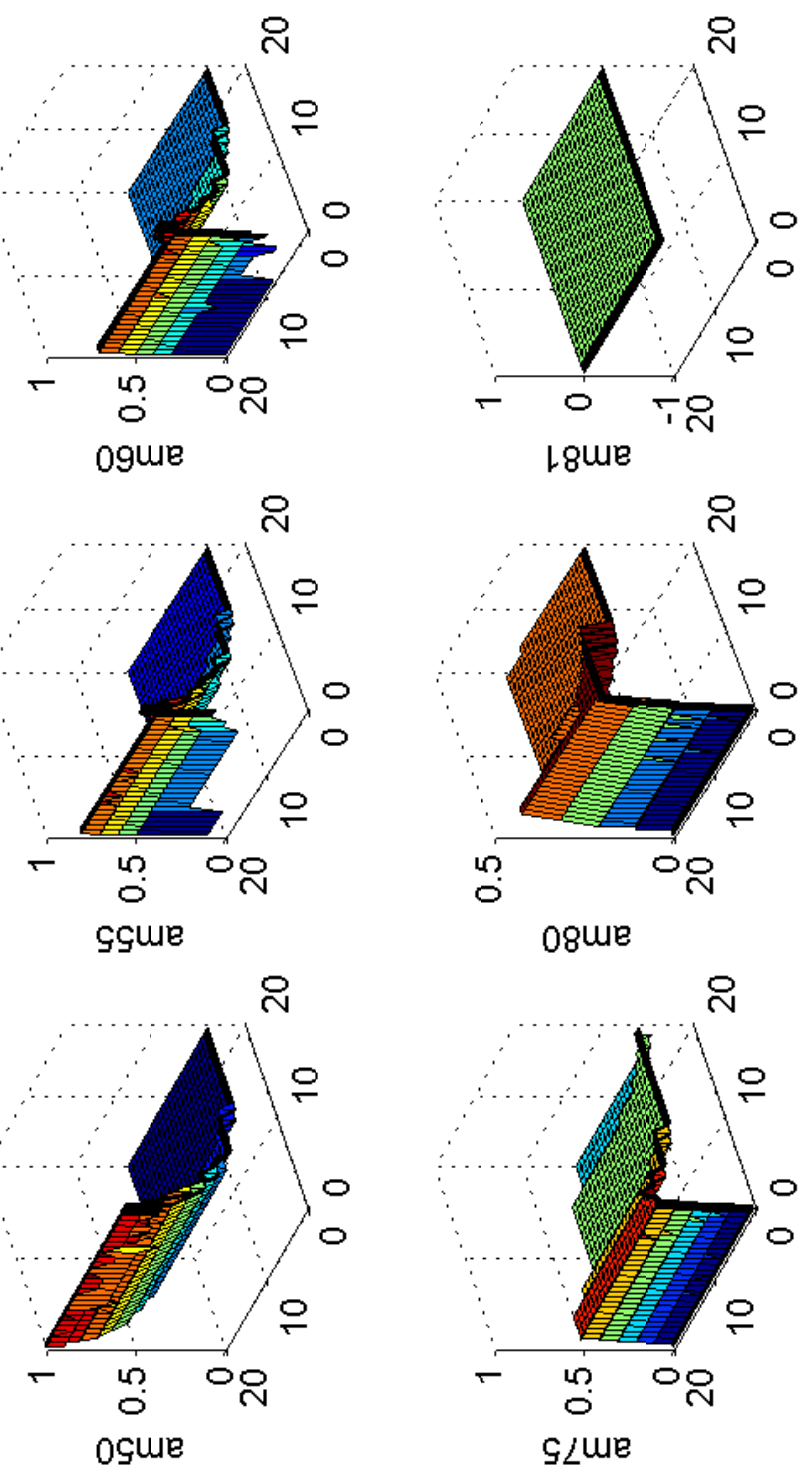

lowe
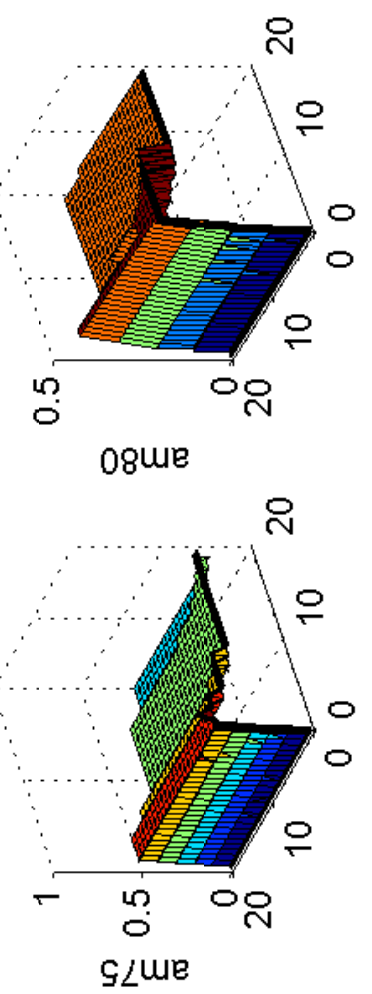
Figure 1-4. Stockholders
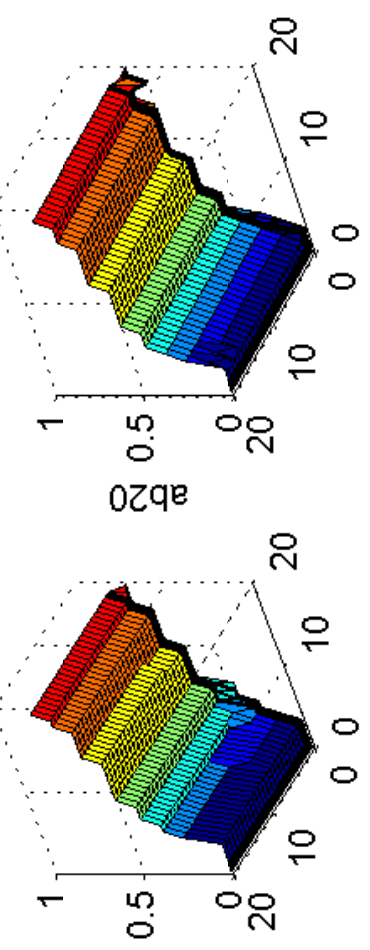

sıqe
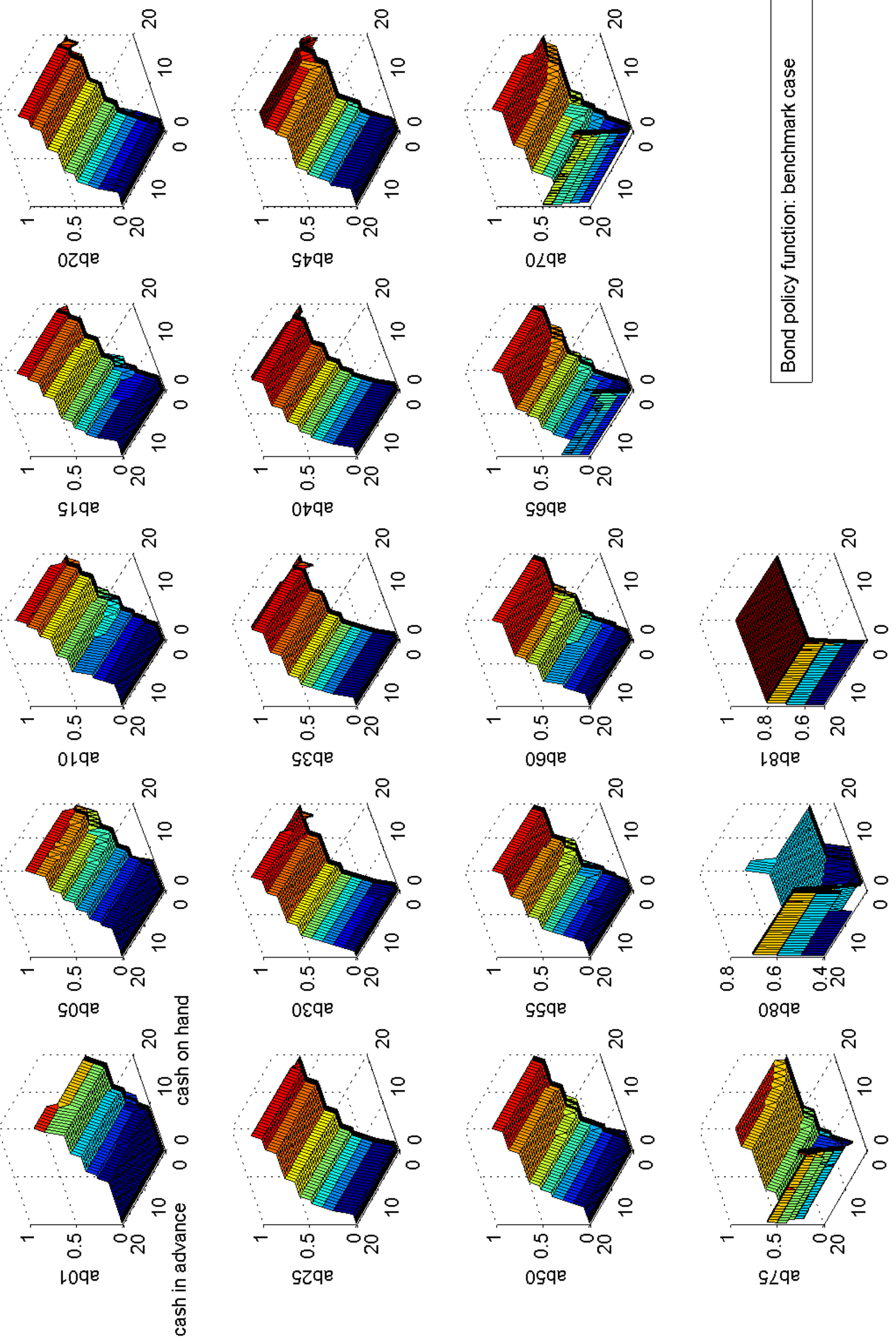
Figure 1-5. Stockholders
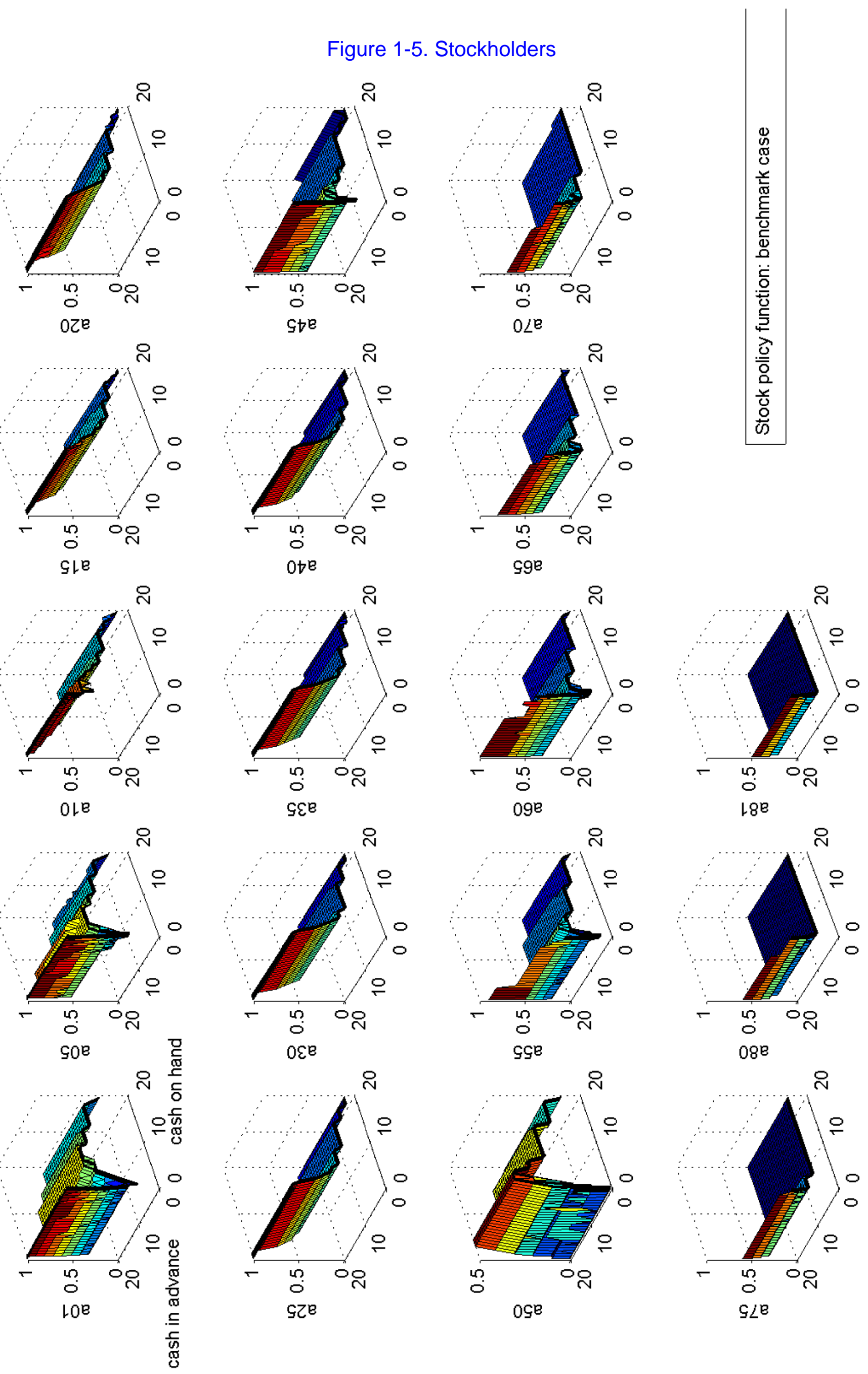
Figure 1-6. Stockholders
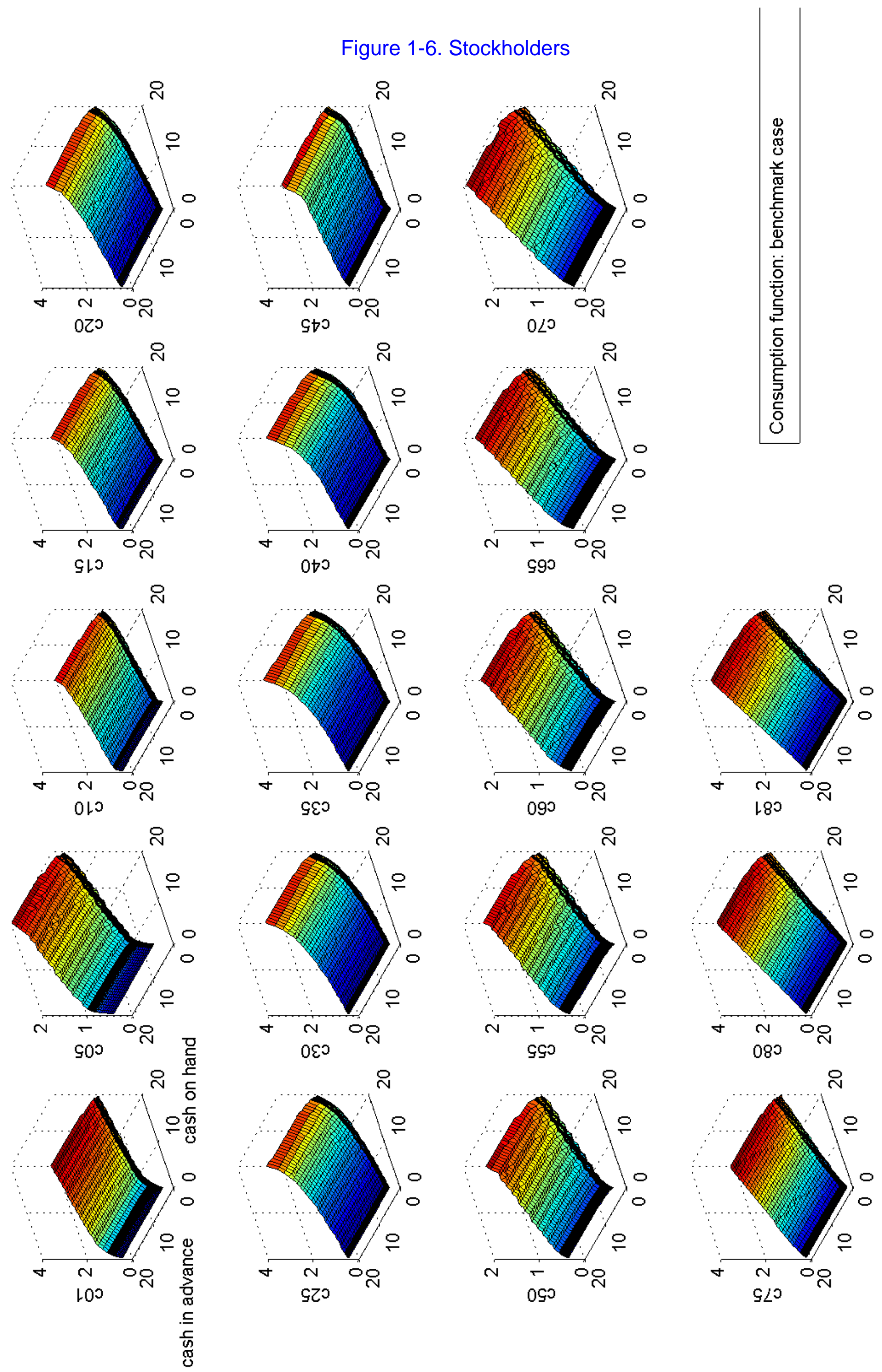
Figure 1-7. Stockholders
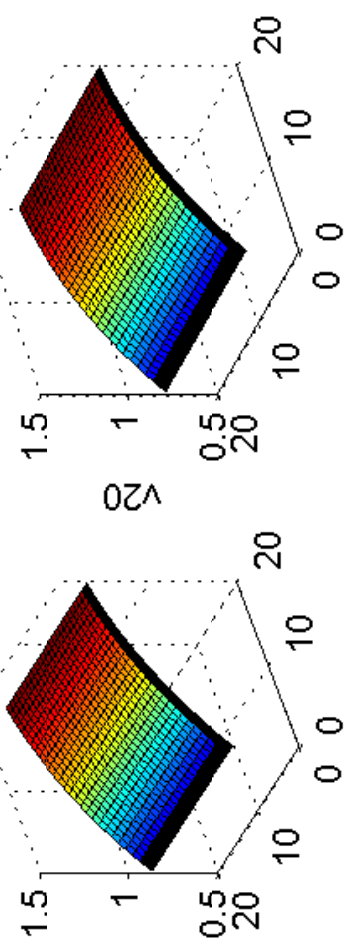

sı^
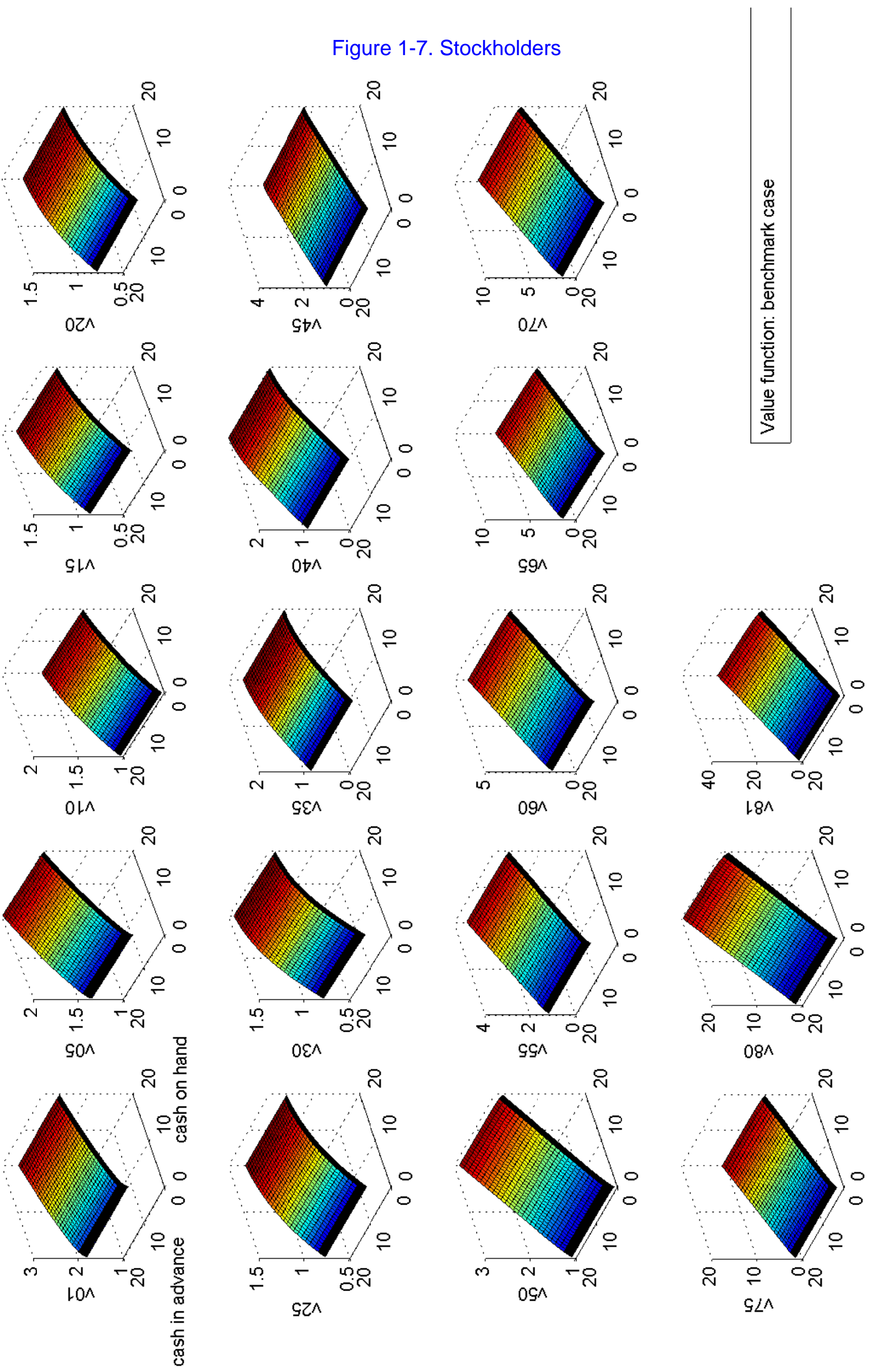
Figure 2-1. Stockholders

mean consumption, wealth, and income: no shopping cost
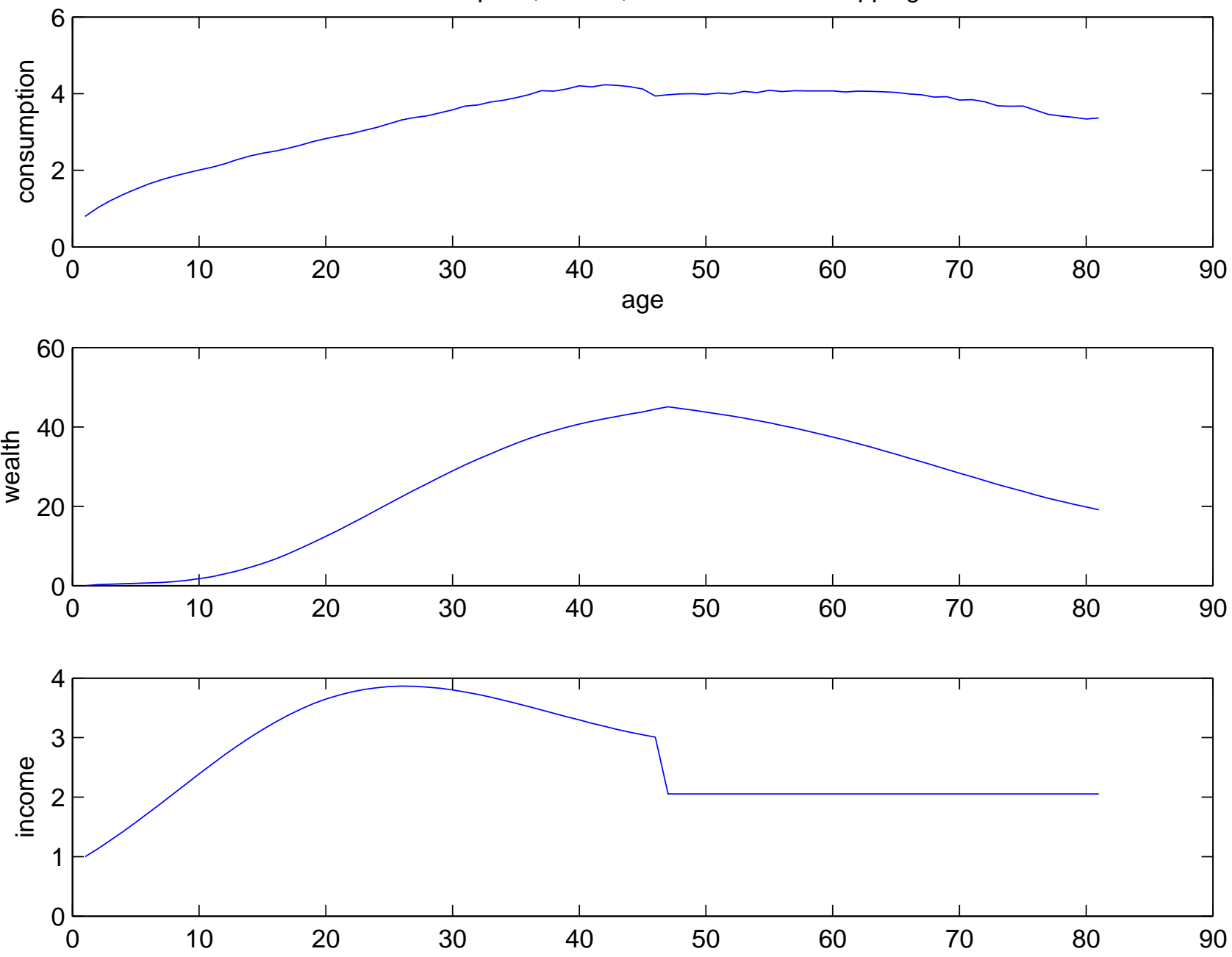
Figure 2-2. Stockholders

mean portfolio: no shopping cost
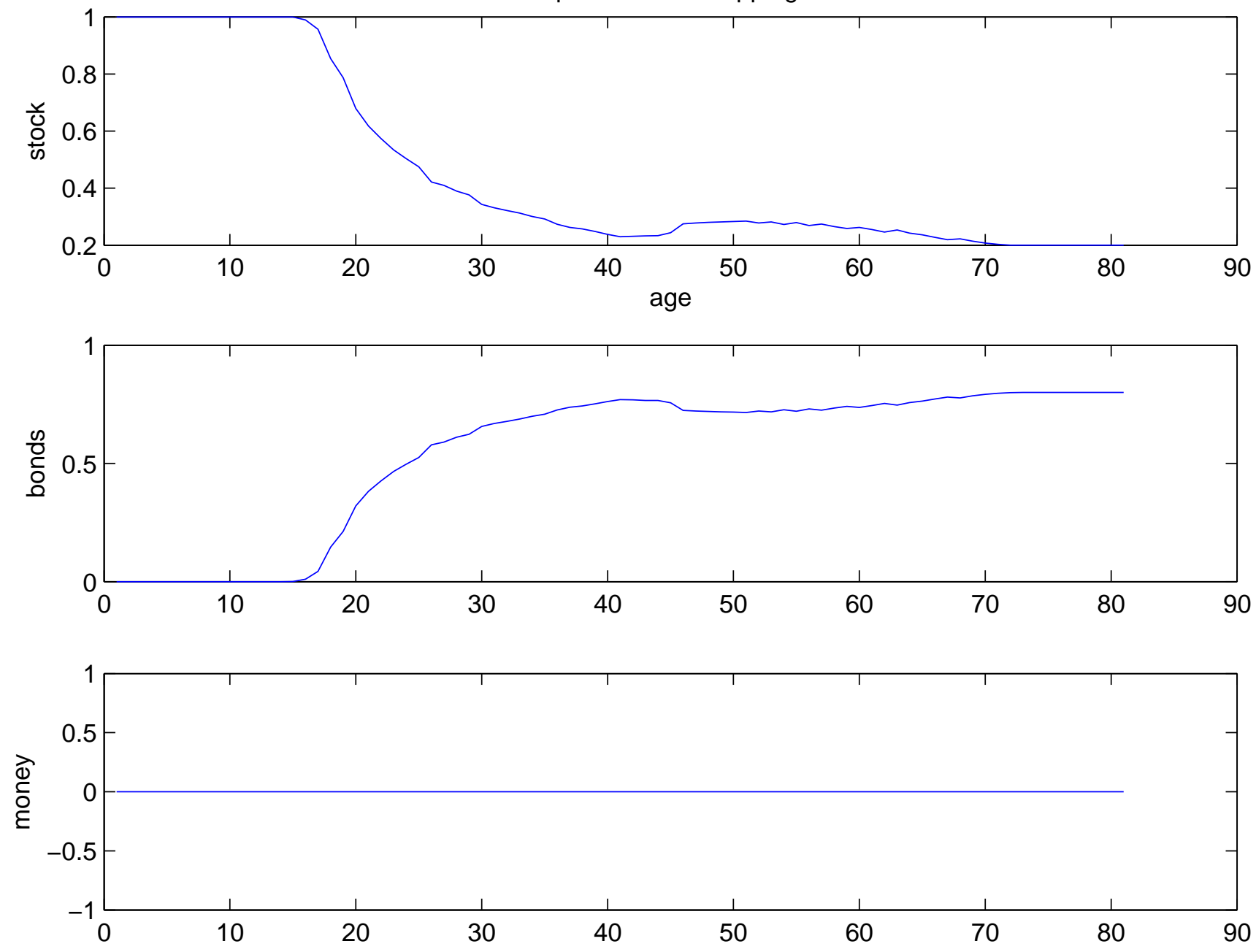
Figure 3-1. Stockholders
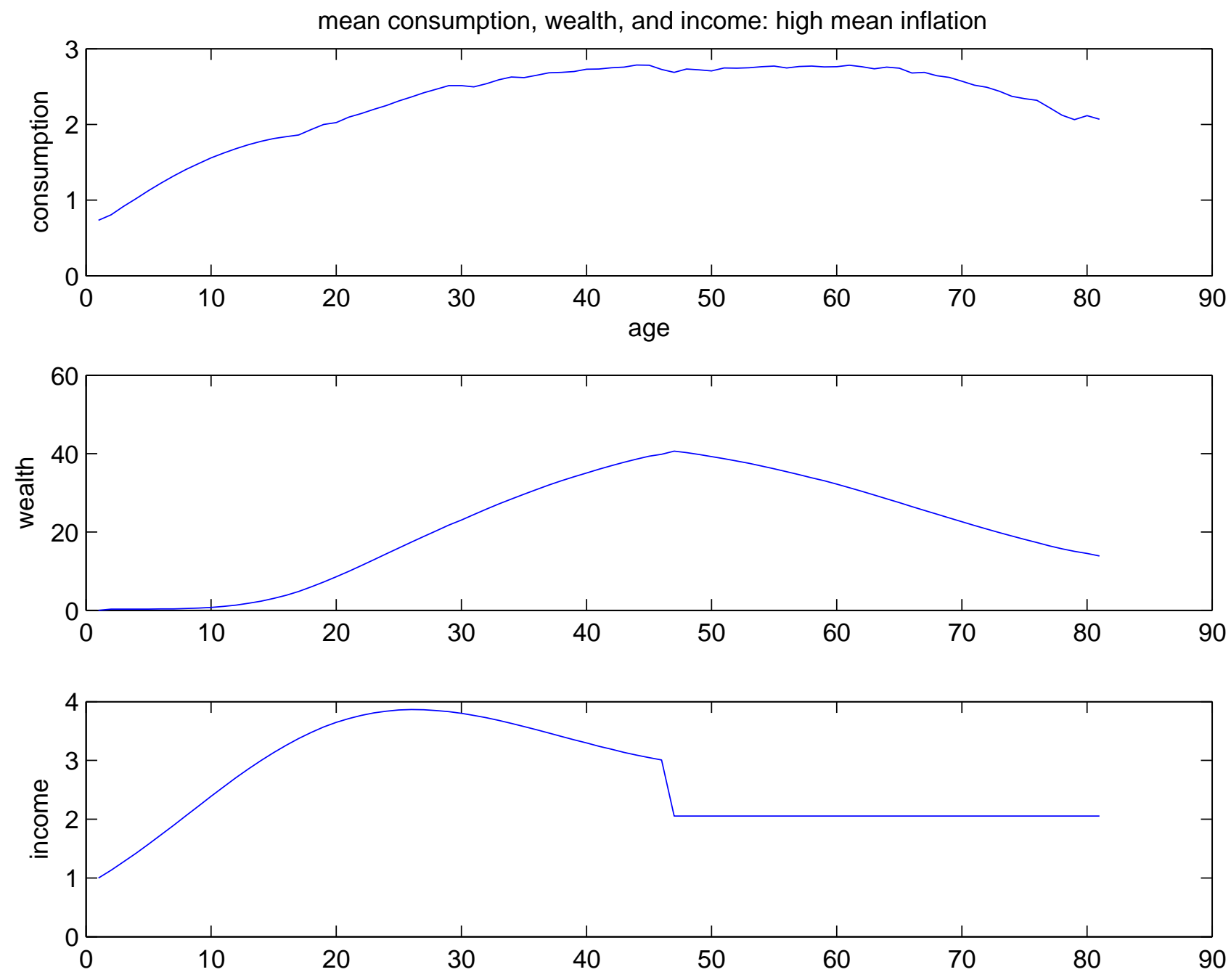
Figure 3-2. Stockholders

mean portfolio: high mean inflation
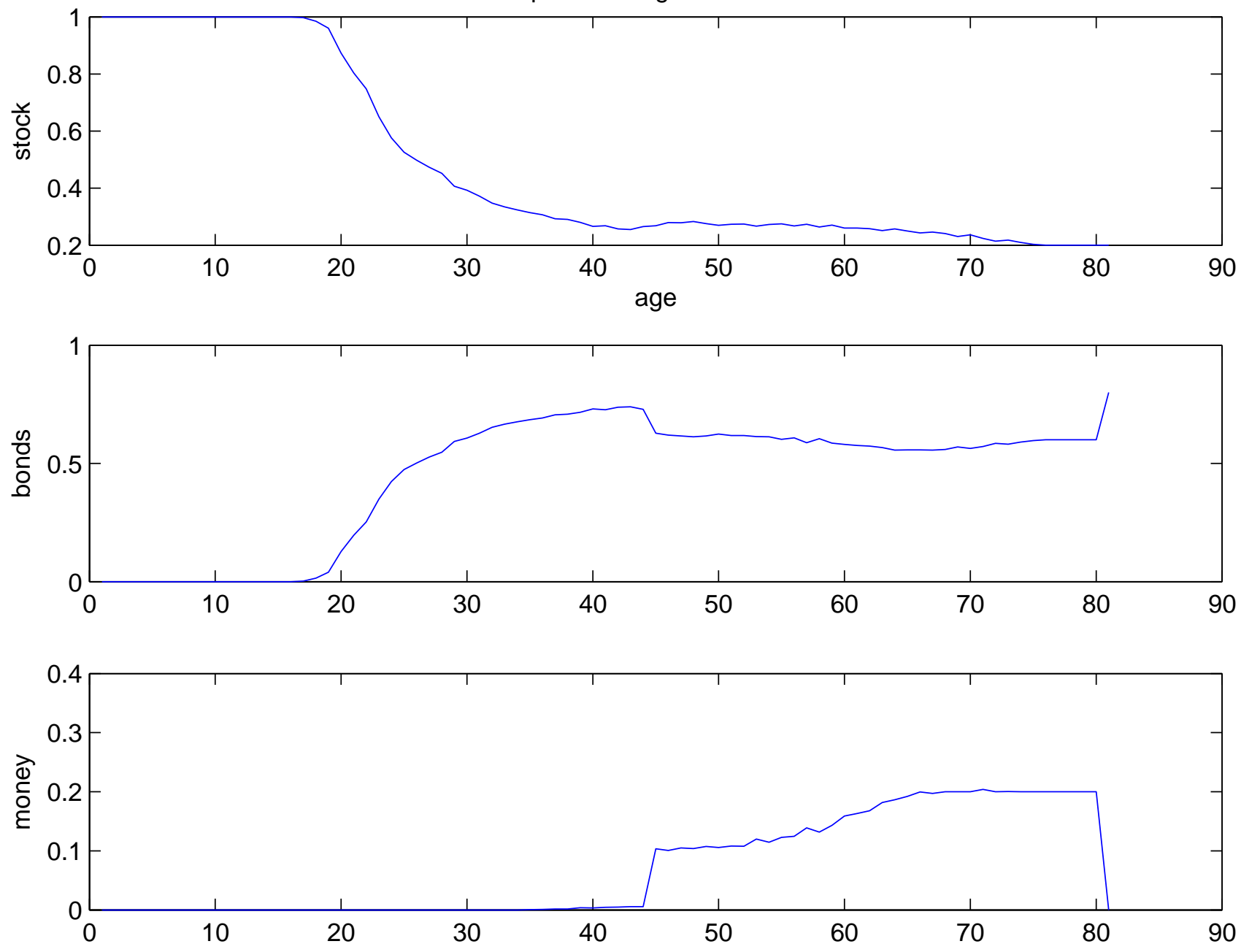
Figure 4-1. Stockholders
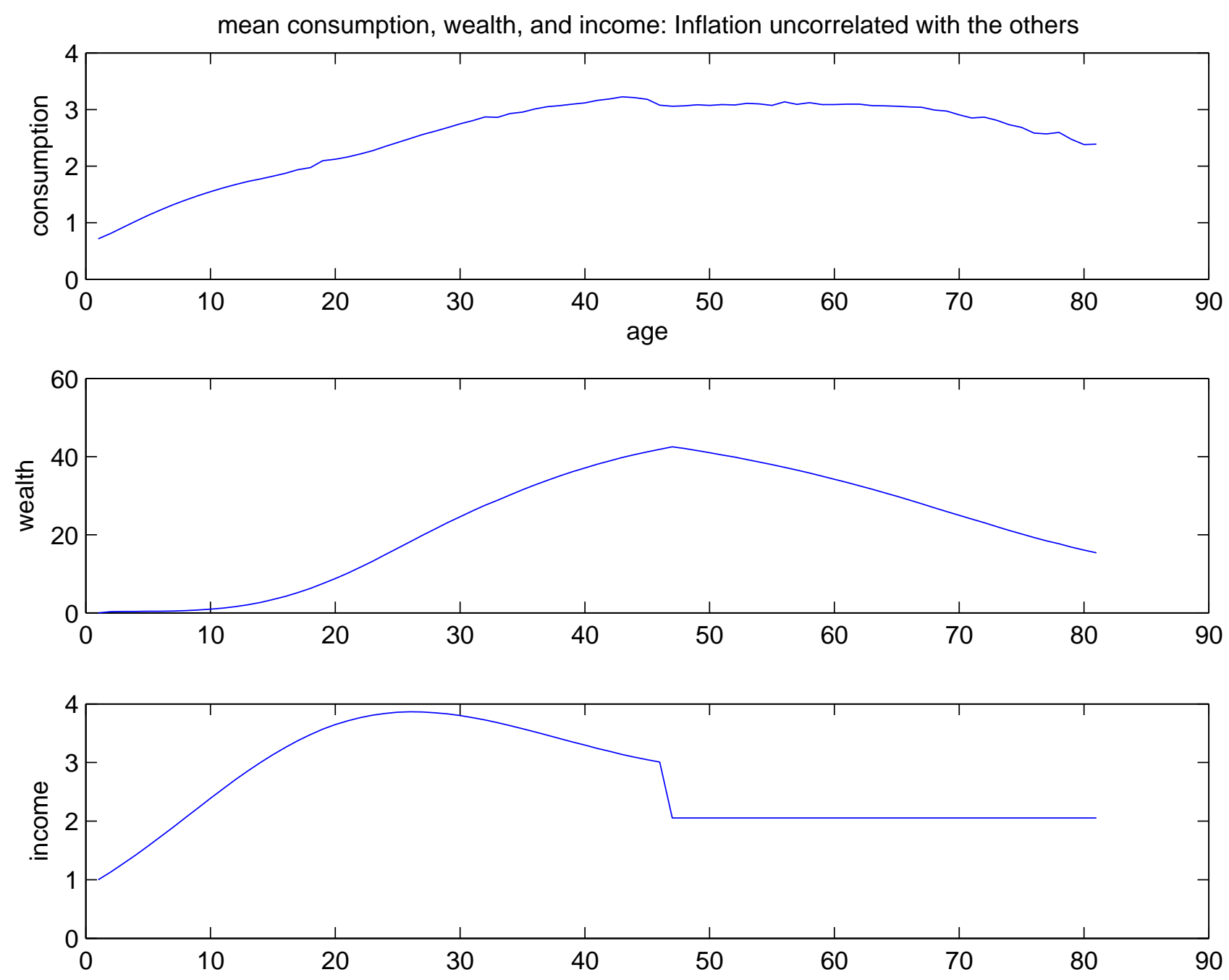
Figure 4-2. Stockholders
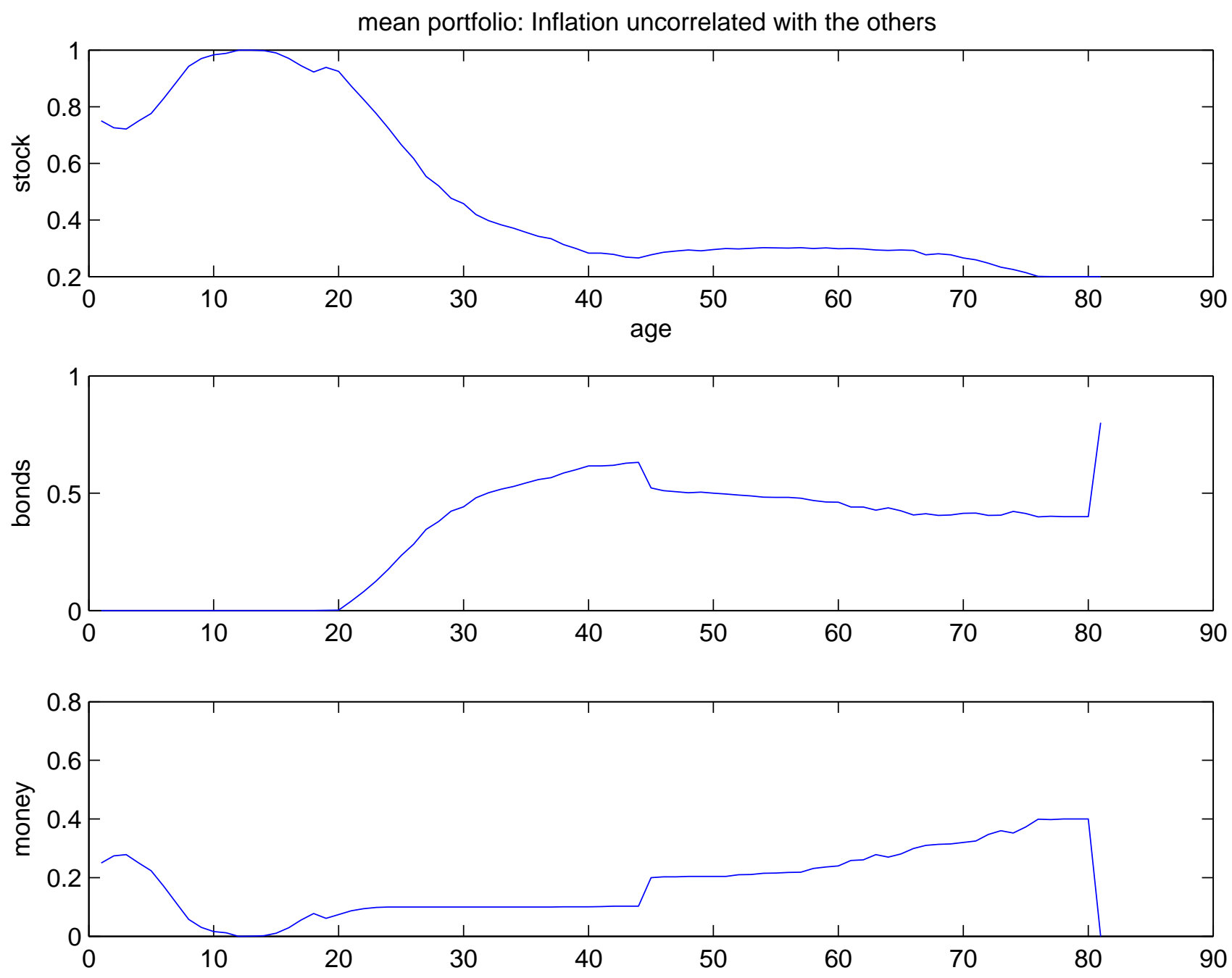
Figure 5-1. Stockholders

mean consumption, wealth, and income: zero corrlations
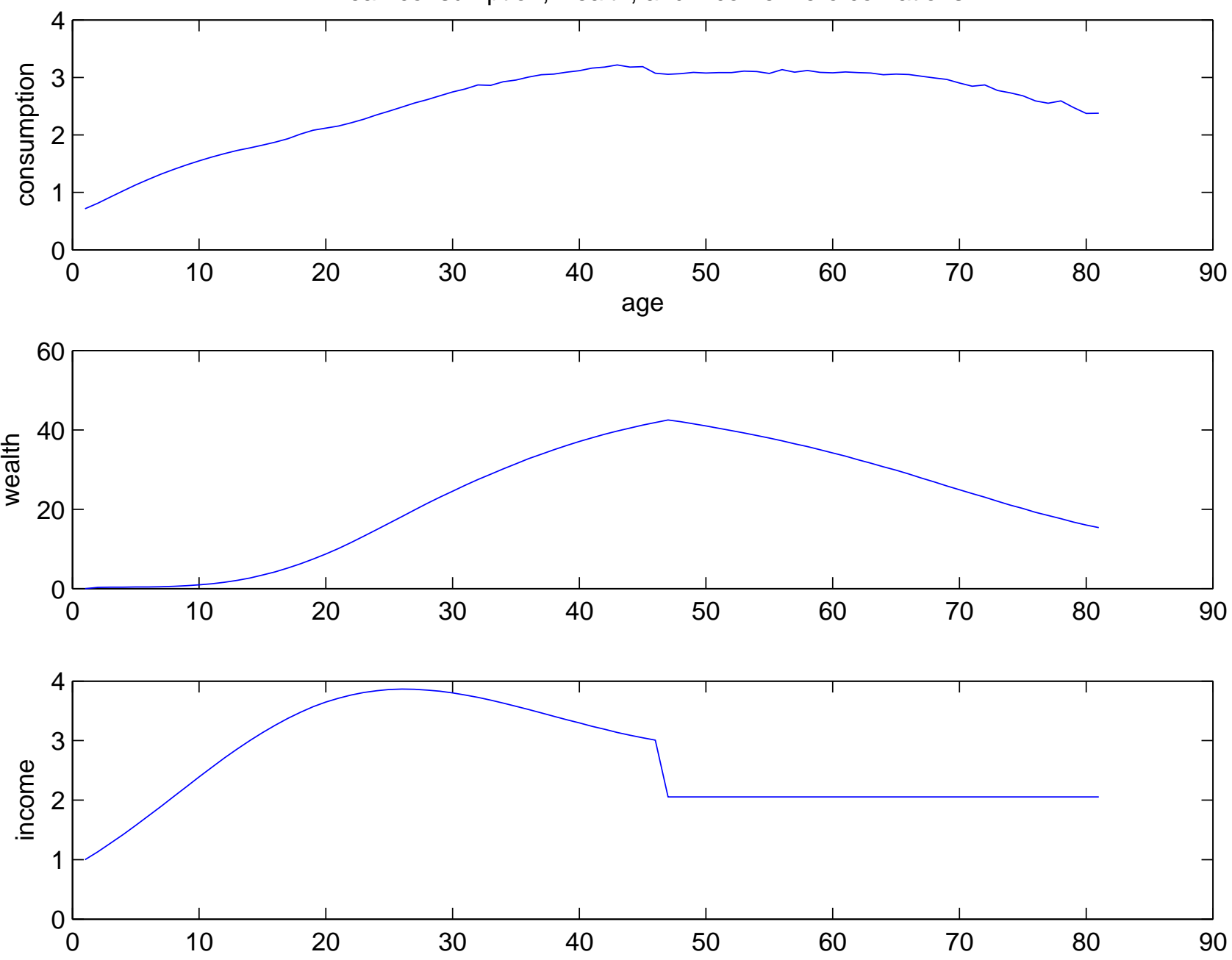
Figure 5-2. Stockholders

mean portfolio: zero corrlations
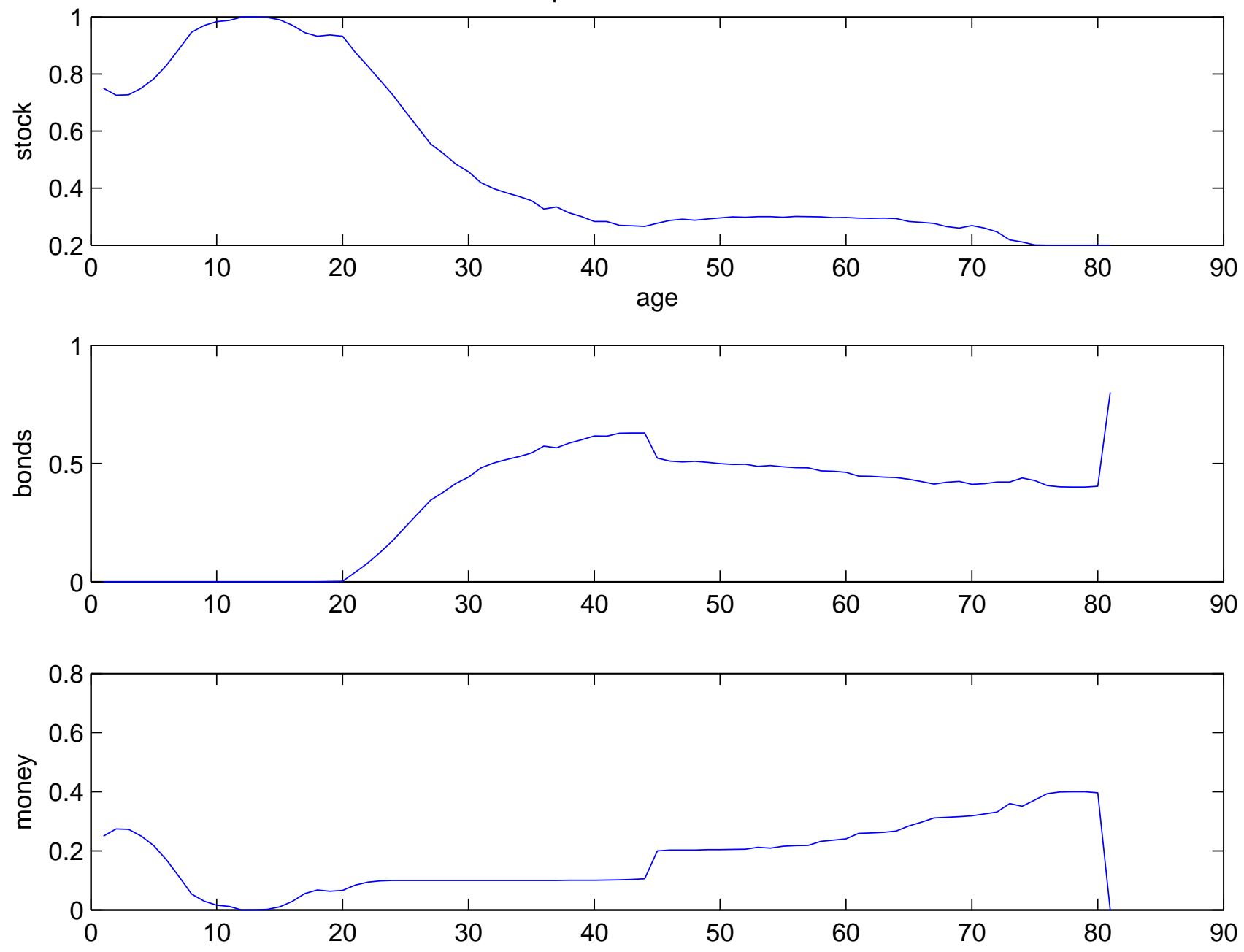
Figure 6-1. Non-Stockholder
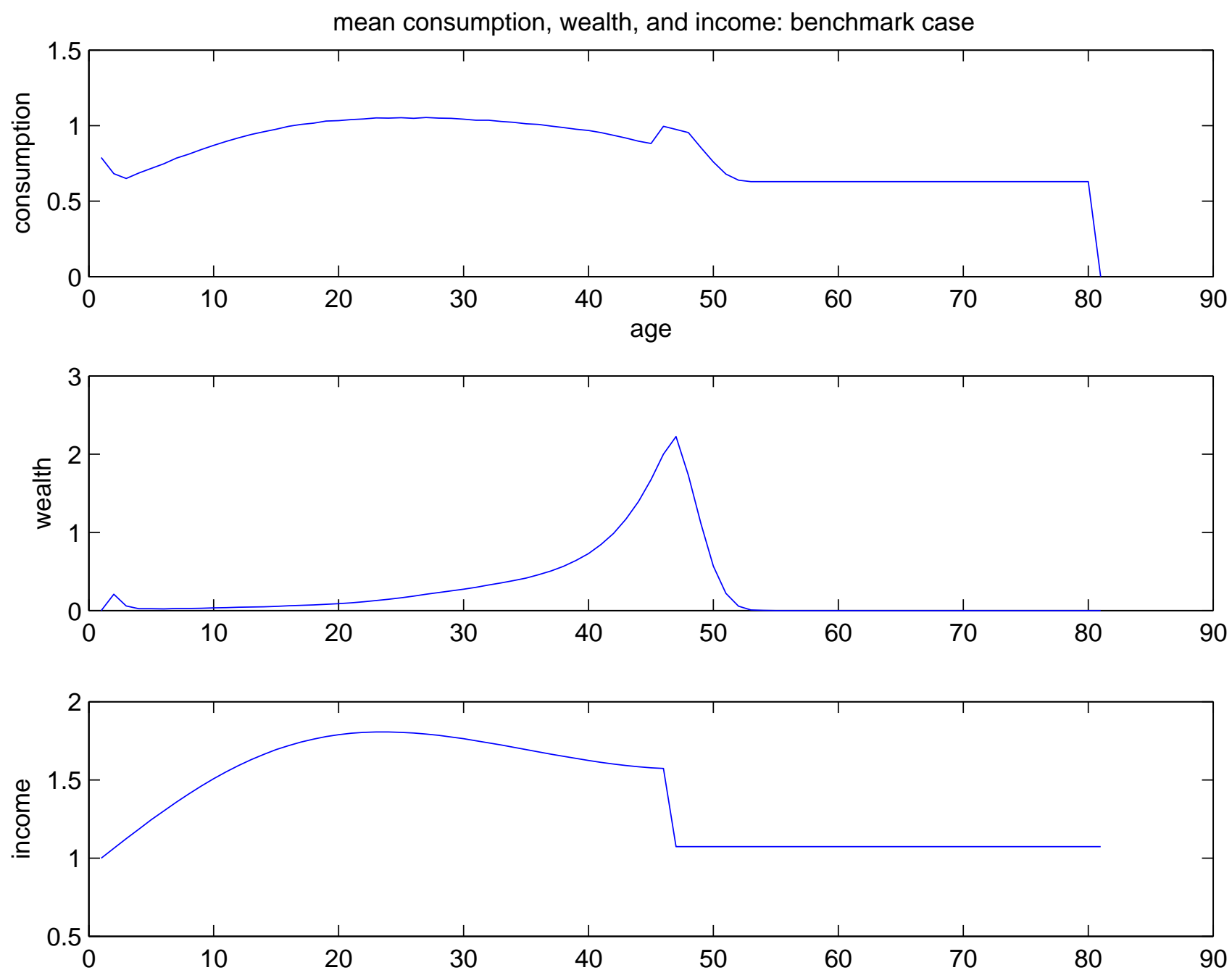
Figure 6-2. Non-Stockholder
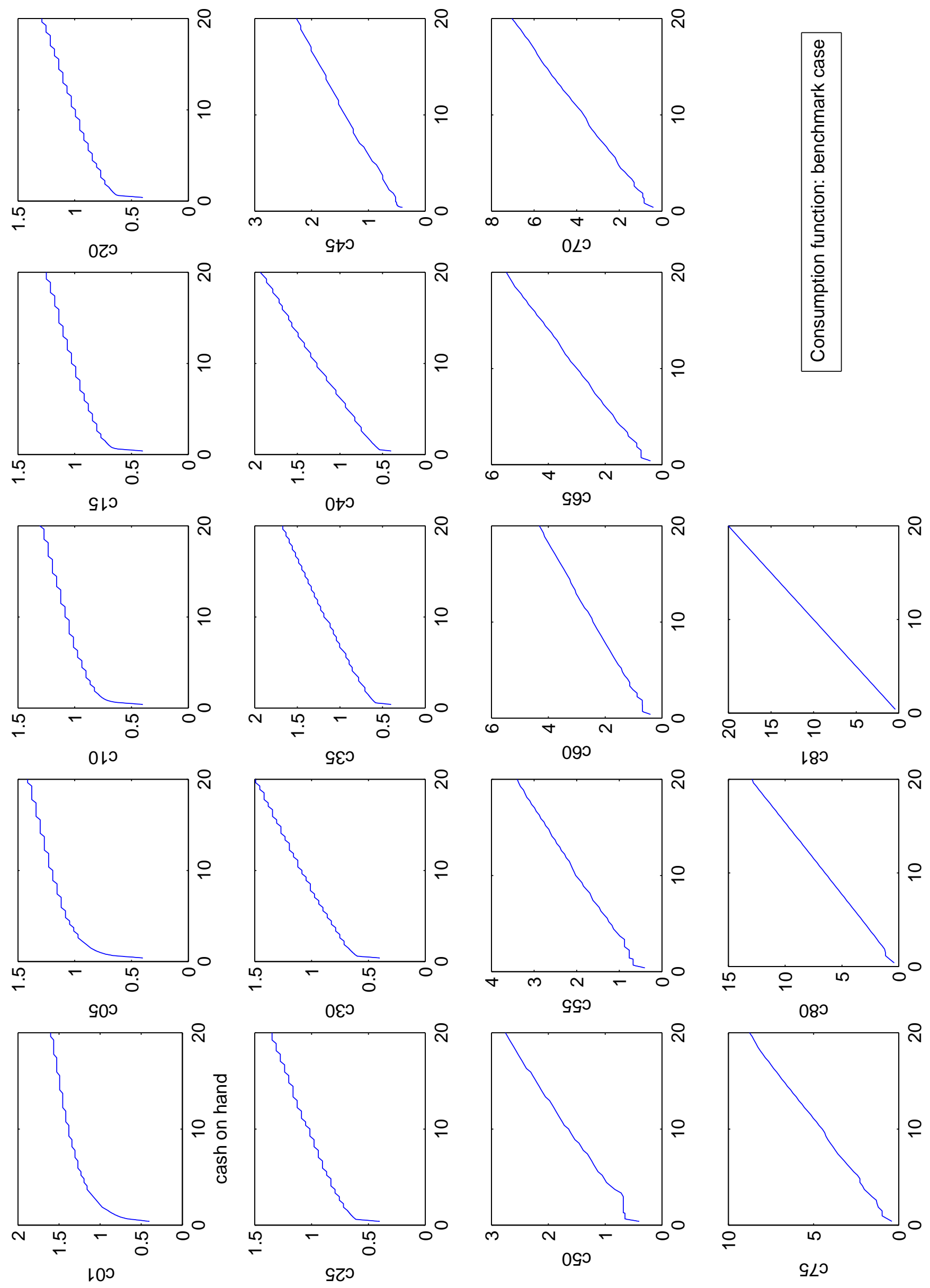
Figure 6-3. Non-Stockholder
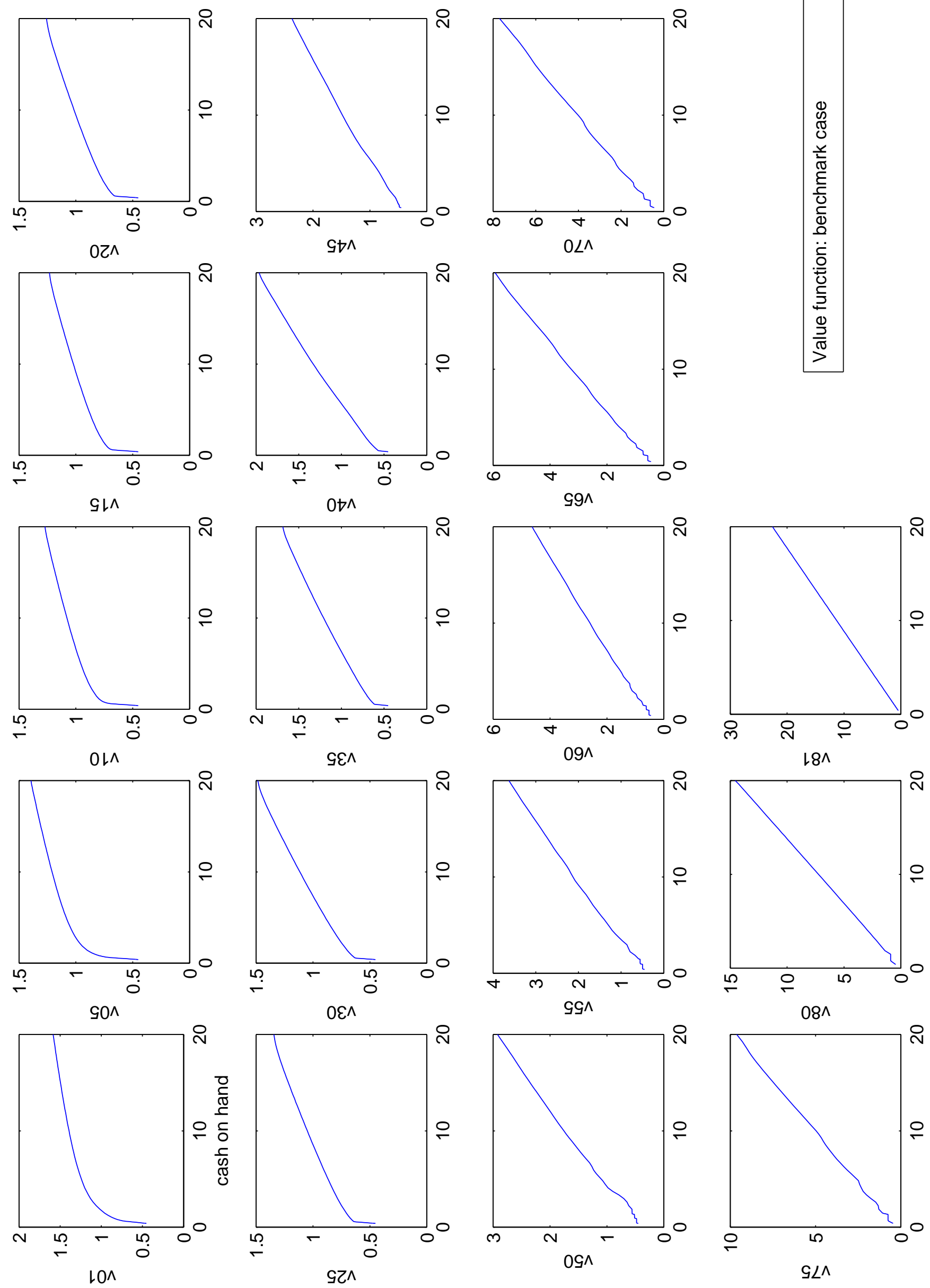
Figure 7-1. Non-stockholders

mean consumption, wealth, and income: no shopping cost
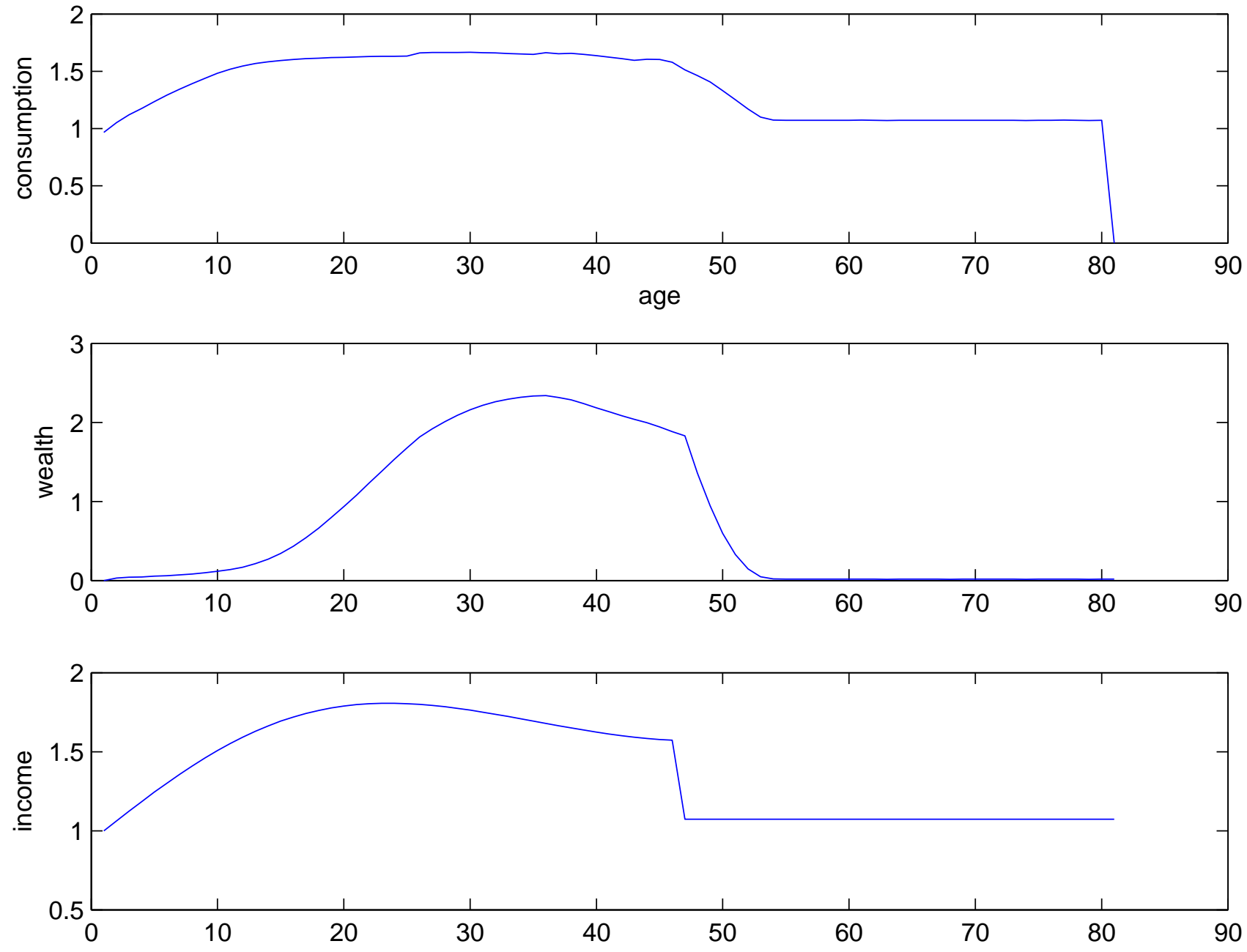
Figure 8-1. Non-stockholder
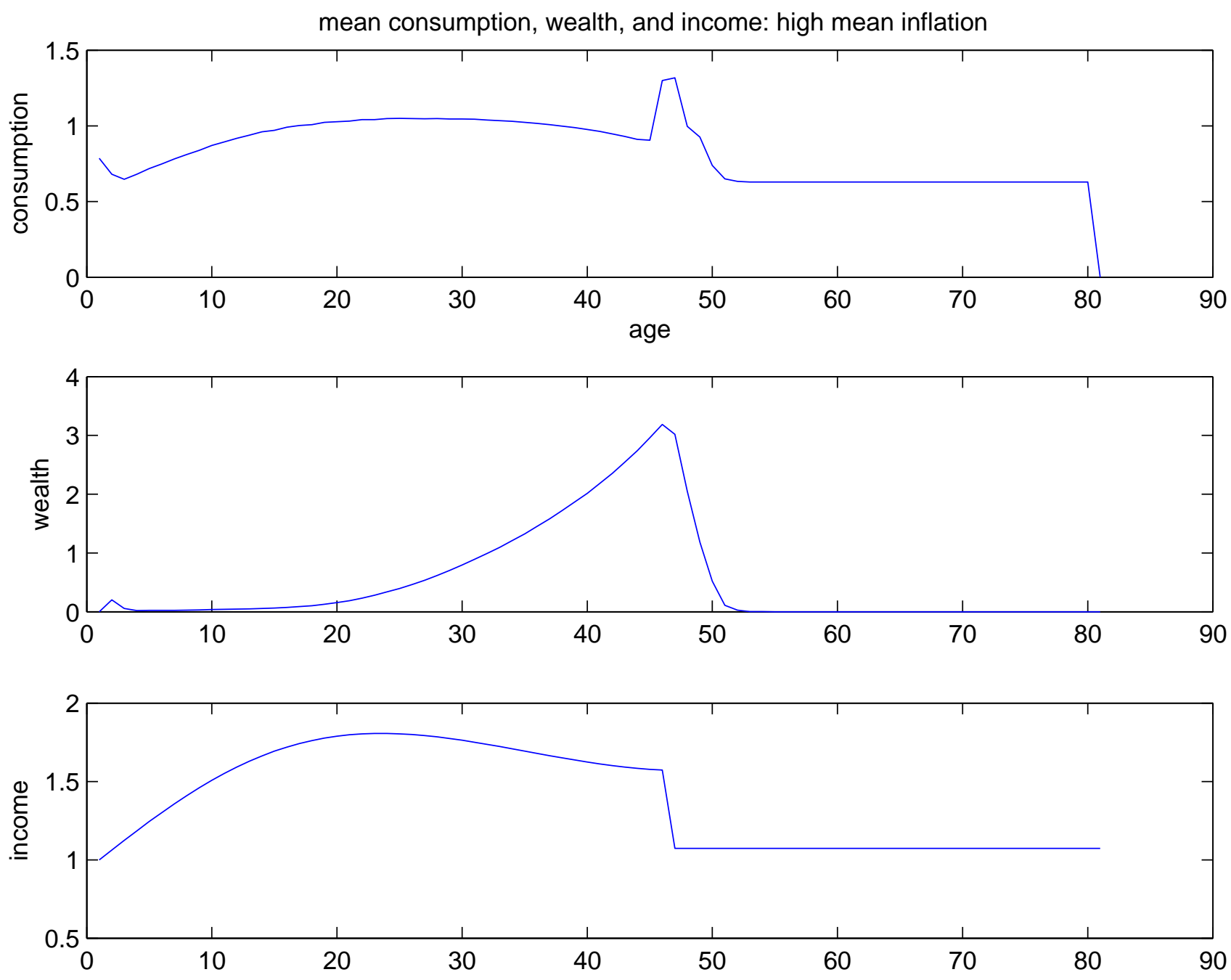